\title{
IMPACTO DE LAS TRANSFERENCIAS CONDICIONADAS DEL PROGRAMA Mas FAMILIAS EN ACCION EN EL MUNICIPIO DE BUCARAMANGA Y SU INCIDENCIA EN EL AHORRO DE CADA FAMILIA BENEFICIARIA
}

\section{INTRODUCCION}

El presente trabajo pretende mostrar los cambios que ha generado en las familias que son beneficiadas con el auxilio recibido, y los cambios que internamente ha tenido el programa.

En sus inicios el programa familias en acción se vio como una iniciativa del Gobierno Nacional era Programa bandera del Gobierno del Doctor Álvaro Uribe Vélez (presidente de Colombia), formaba parte de la Agencia Presidencial para la Acción Social y la Cooperación Internacional "Acción Social", que consistía en la entrega de subsidios económicos de nutrición y educación condicionados al cumplimiento de una verificación realizada bimensualmente, cumplido este requerimiento la familia cobrada el incentivo mediante la modalidad de una carta cheque que le era entrega a la madre titular y debía ser cobrada en el entidad financiera autorizada la cual no era acumulable, no se podían guardar estos títulos de cobro si la titular no cobraba esto se veía reflejado a los dos meses en el cobro siguiente; El auxilio va cambiando con la edad del beneficiario y era entregado hasta que cumpliera la mayoría edad (18 años).

Al empezar un nuevo gobierno el doctor Juan Manuel Santos (presidente de Colombia) tomo como iniciativa fortalecer el programa presentando el proyecto de Ley que convirtió al programa ley de la República en junio de 2012, con la ley 1532, creando a Más Familias en Acción, y perteneciendo al Departamento para la prosperidad "DPS" (antes Acción Social), realizando cambios, y fortaleciendo lo que se venía haciendo en el programa, la verificación tanto de salud como educación se trasladó directamente a los IPS, EPS y Entidades Educativas, se amplió el tiempo de permanencia de un beneficiario que tenía cumplida su mayoría de edad (18 años) y estaba cursando su último grado se le cancelaria hasta el final del año escolar. 
En la cancelación de incentivos se implementó el pago por medio de las TMC (transferencias monetarias condicionadas) y se inició el proceso de bancarización de las madres titulares, que consistía en la apertura de una cuenta de ahorros y la entrega de la tarjeta debito para que iniciaran cobros en los diferentes cajeros, en el momento del pago del incentivo económico se realiza la liquidación del valor a cancelar a cada familia y de la Cuenta del Tesoro Nacional les realizan la transferencia a cada una de las cuentas el valor liquidado para que sea cobrado en cualquier cajero de la RED ATH.

Al inicio de estos cobros fue difícil que las titulares se acostumbraran a este tipo de cobro y se realizaron jornadas de capacitación conjuntamente con el banco para que conocieran el Cajero automático y su uso.

El paso a seguir con las beneficiarias es crear la cultura del ahorro, tenga una vida crediticia y puedan acceder a otros programas que el gobierno Nacional implemente para ayudar a mejor las condiciones de vida de las familias, a contribuir en la formación de capital humano complementar el ingreso de las familias con niños niñas y adolescentes y a bajar los índices de pobreza.

En el desarrollo de la presente investigación con los cambios que ha venido realizando el programa y la implementación de nuevos programas como son:

- La Bancarización.

- Jóvenes en Acción.

- Mujeres ahorradoras.

Se realizaron una serie de encuestas que permiten realizar un estudio a los hogares de las familias beneficiarias de más familias en acción de la ciudad de Bucaramanga, que permite analizar el uso de los recursos, la incidencia en el Ingreso económico de las familias y la capacidad de ahorro de cada familia. 


\section{CAPITULO I}

\section{Revisión de la Literatura}

Los hogares han desarrollado estrategias de manejo y de cubrimiento de riesgo para enfrentar estas variaciones, en un contexto caracterizado por escasa contribución del sistema financiero formal (Dercon, 2002).

Las variaciones en los ingresos de los hogares -o el riesgo en el ingreso-, pueden ser anticipadas o no (Morduch, 1995); Deaton, 1992) y se generan por diferentes factores (Dercon, 2002). Por un lado, los shocks de tipo idiosincrático se definen como aquellos que afectan de manera particular a un individuo u hogar de una comunidad; ejemplos de este tipo de shocks son la muerte o enfermedad de algún miembro del hogar, pérdida del empleo o accidentes. Por otro lado, los shocks de tipo sistémico o comunes, son riesgos agregados, que afectan a todos -o a la mayoría- de los miembros de una comunidad o región (Dercon, 2002). Entre los shocks comunes se encuentran factores climáticos que afectan cosechas, desastres naturales, derrumbes, inundaciones ó situaciones de conflicto.

Las posibilidades de tratar las consecuencias de un shock determinado dependerán de su naturaleza: mientras los shocks idiosincráticos pueden ser asegurados dentro de una comunidad, los shocks sistémicos no, porque si todos los miembros de la comunidad son afectados, el riesgo no puede ser compartido (Dercon, 2002).

Las estrategias para suavizar el ingreso, conocidas también como mecanismos ex ante, pueden anticipar shocks y tienen como propósito afectar el grado de riesgo en el ingreso; entre estas estrategias sobresale la diversificación de cultivos, la diversificación de actividades ocupacionales al interior del hogar y la migración estacional (Alderman y Paxon, 1994, Rosenzweig and Binswanger, 1993; Morduch, 1990). Los mecanismos de suavización del ingreso con usualmente utilizados por el hogar ó por un individuo, pero también pueden involucrar a vecinos, familiares o grupos de conocidos (Fafchamps, 1992).

Por otro lado, las estrategias para suavizar el consumo, ó mecanismos ex post, permiten a los hogares enfrentar el riesgo después de haber sufrido drásticas caídas en el ingreso; estos mecanismos buscan aliviar las 
consecuencias de la variación en el ingreso. Entre las estrategias de suavización del consumo se destacan los auto-seguros (como el uso de ahorros preventivos), la venta de activos, los préstamos de emergencia y mecanismos grupales que permiten compartir el riesgo (Morduch, 1997).

Las estrategias para suavizar el ingreso y el consumo también se conocen como mecanismos de manejo de riesgo (ex ante) y mecanismos para enfrentar el riesgo (ex post), respectivamente (Alderman y Paxson, 1994).

Los hogares pueden asegurarse ellos mismos a acumular activos durante períodos de buenos ingresos para utilizarlos durante períodos malos. Los ahorros preventivos pueden llegar a ser muy efectivos para los hogares que enfrentan variaciones en el ingreso (Deaton, 1991). Los hogares utilizan diversas formas de ahorro no convencional tales como comprar animales domésticos, joyas ó materiales de construcción, almacenamiento de granos, entre otros. No obstante, algunos de estos tipos de ahorro son más líquidos que otros y de ahí su efectividad como estrategia de suavización del consumo.

Es posible también que emerjan arreglos informales entre miembros de un grupo o comunidad para apoyarse mutuamente en caso de una adversidad o calamidad. Estos mecanismos son frecuentes dentro de las familias, grupos étnicos y grupos de vecinos. Otra forma de enfrentar variaciones ex post en el ingreso es buscar la manera de obtener dinero extra cuando se presenta un infortunio (Dercon, 2002).

Los mecanismos grupales de seguros buscan aliviar los shocks idiosincráticos de algunos de los miembros - pero no de todos. Por tanto, este tipo de seguros informales no pueden proveer alivio a shocks sistémicos que afecten a todos los miembros del grupo (Dercon, 2002). Un ejemplo serían contribuciones de los miembros de un grupo u organización para propósitos específicos como muerte o enfermedad de algún integrante de los hogares.

Aunque existen diferencias conceptuales entre mecanismos de suavización del ingreso y mecanismos de suavización del consumo, en la práctica es muy difícil saber cuál tipo de estrategia está siguiendo un hogar. De hecho, estos dos tipos de mecanismos pueden actuar como complementos o sustitutos (Morduch, 1995). Los hogares adoptan varios tipos de estrategias de suavización del consumo y del ingreso simultáneamente y, en algunos casos, estrategias como el crédito pueden ser utilizadas como instrumentos ex ante 
y ex post para el manejo del riesgo. En el mismo sentido, como Dercon (2002) anota, son pocos los shocks que sean exclusivamente idiosincráticos o exclusivamente sistémicos.

A pesar de la existencia de estrategias para enfrentar shocks y estacionalidades en hogares vulnerables, le evidencia muestra que la variabilidad en el consumo se mantiene porque en general estos mecanismos son insuficientes y su utilización es, en cierta medida, limitada (Townsend, 1995; Rosenzweig, 1988; Deaton, 1992).

Derco (2002) -apoyado en los resultados de Jalan y Ravallion (1997), Dercon (1996), Rosenzweig y Binswanger (1993), Dasgupta (1993) y morduch (1990)-, arguye que las fluctuaciones en el consumo usualmente implican altos niveles de pobreza transitoria y que el riesgo en el ingreso puede ser una causa de pobreza persistente. La evidencia indica que cuando los hogares son incapaces de enfrentar variaciones en el ingreso, ésta situación se refleja no sólo en fluctuaciones en el consumo, sino que afectan la nutrición, la salud y la educación (Jacoby y Skoufias, 1997; Rose, 1999; Foster, 1995; Behrman y Deolalikar, 1990).

Se ha demostrado que algunos servicios financieros (créditos, depósitos, instrumentos de pago, entre otros) pueden ofrecer alternativas de bajo costo para suavizar el ingreso de los hogares ya que permiten a los hogares sacar provecho de sus oportunidades productivas, facilitan suavizar el consumo en presencia de flujos de ingreso inestables o estacionales y ofrecen herramientas para el manejo del riesgo ante shocks en el ingreso (Sharma y Zeller, 1999; González-Vega, 2003, 1998). Sin embargo, el sistema financiero formal aún se muestra tímido y reticente frente a la posibilidad de asegurara estos altos riesgos en los ingresos de los hogares pobres; los mercados de seguros y de crédito para estos casos son, en el mejor de los casos, incompletos si no ausentes. De ahí la importancia no solo de identificar las estrategias de suavización del ingreso y el consumo de los hogares en condición de pobreza o vulnerabilidad, sino de comprender a profundidad el funcionamiento de esos mecanismos como insumo para el diseño de políticas, estrategias y servicios que permitan la inserción efectiva de esta población en el sistema financiero formal 


\subsection{Focalización de Familias y Atención de la Pobreza}

La selección de las familias potencialmente beneficiarias es proceso inicial y más importante del programa, conocido como focalización. Familias en Acción estadirigido a las familias pobres y vulnerables del país, y su identificación y selección requiere de instrumentos metodológicos legalmente reconocidos, mediante los cuales se garantice que la utilización de los recursos públicos orientados al gasto social, se realiza de manera efectiva y eficiente.

El programa realizo la focalización en dos etapas, una territorial y otra poblacional. En la focalización territorial, además de los criterios de pobreza para la selección de los municipios o localidades elegibles, se establecieron los requisitos orientados a garantizar su operatividad. La focalización poblacional implico la identificación de criterios de pobreza y vulnerabilidad que correspondieron a la selección de las familias pobres, en situación de desplazamiento y a las indígenas.

La focalización racionaliza el gasto público para lograr niveles de eficiencia en la entrega de los recursos estatales a los más necesitados, ante el supuesto de que el gasto social llega en menor proporción a este grupo poblacional. Es una política que identifica de manera selectiva a los sectores más pobres, por medio de indicadores que miden y establecen las prioridades de la inversión estatal. A su vez, con este instrumento, se espera lograr una mayor eficiencia en el uso de los recursos mediante la reducción de los costos de gestión y ejecución, dado el uso mas preciso de la información social.

"La focalización es una herramienta que algunas veces emplean los gobiernos para que un programa sea eficiente y no constituye un fin en si mismo. Qué tanta focalización efectuar y còmo hacerlo depende de las respuestas especificas a cada programa en cuanto a si las ganancias superan los costos “ (Grosh et ál., 2008).

En el país el instrumento básico para la identificación y selección de las familias objeto de los programas sociales ha sido el Sisben, mediante el cual se obtiene información que permite clasificar a los hogares y familias según sus condiciones socioeconómicas particulares, medidas por un indicador resumen de calidad de vida. Las variables para la construcción de este indicador se determinan a partir de la información recogida en las Encuestas de Caracterización Socioeconómica, diseñadas por el Departamento 
Nacional de Planeación (DNP) y diligenciadas por las diferentes administraciones municipales.

La Ley 60 de 1993 expresa en el articulo 30 "Defínase focalización de subsidio al proceso por el cual se garantiza que el gasto social se asigna a los grupos de población mas pobres y vulnerables". En cumplimiento de esta ley, el Conpes Social, en el documento 22 de 21 de enero de 1994, propone al Sisben como el instrumento a utilizar para la focalización del gasto publico social, y la resolución 65 de 25 de marzo de 1994 del Conpes determina tomar el Sisben como herramienta técnica a utilizar desde el año 1993 para la identificación de los potenciales beneficiarios del gasto público social. Esta herramienta de identificación genera puntajes en una escala de 0 a 100 obtenida mediante la técnica de componentes principales categóricos. $D$ este modo, si un hogar obtenía el puntaje o era de esperarse que sus condiciones de vida fueran las más precarias en contraste a un hogar que obtuviera el puntaje 100.

El instrumento consta de un cuestionario que se aplica a los individuos para obtener información de empleo, ingresos, características de la vivienda y demográficas, educación y servicios públicos, entre las variables más importantes. Por medio de un proceso sistematizado se ordena a la población por pobreza de manera continua, asignándole a cada individuo un puntaje entre 0y 100. La población así ordenada se divide en seis niveles, los más pobres se ubican en los primeros niveles. La identificación en el nivel individual de los potenciales hogares beneficiarios ser realiza mediante la prueba de aproximación de medios, bajo responsabilidad de las administraciones municipales, según directrices de la Dirección de Desarrollo Social (DDS) del DNP, que centraliza las bases de datos correspondientes a todos los municipios del país.

A partir de 2003 la metodología para la generación de los puntajes y los puntos de corte del Sisben fueron modificados atendiendo a una evolución realizada para solucionar algunos inconvenientes ( Conpes Social 055 de 2001). Así, para el nivel 1 del Sisben, metodología 1993, el punto de corte es de 0 a 36 puntos en las zonas urbanas, y de 0 a 18 en las rurales; en 2003, los cortes para las zonas urbanas y rurales son de 0 a 11 y de 0 a17,5 respectivamente.

La focalización de subsidios a la demanda abarca tres dimensiones: la identificación de los beneficiarios, la selección y la asignación. La primera 
consiste en la recolección de la información necesaria para esclarecer las condiciones que posee la población. En caso del Sisben, la información se levanta en las fichas diseñadas que sirven de base para la generación de los puntajes de los hogares y para su clasificación en los seis niveles socioeconómicos; este proceso se realiza de manera descentralizada en cada municipio. La segunda se refiere a la selección de beneficiarios, corresponde al ejercicio de establecer puntos de corte, una vez identificada la población objetivo del programa. En el caso de Familias en Acción, la selección de las familias potenciales corresponde a las del nivel 1 del Sisben con menores de 18 años. Por su parte, la Asignación, es el proceso de entrega a la población identificada y seleccionada del bien o servicio en dinero o especie.

\subsection{Ingresos Para Alternativas Productivas}

El programa Más familias en acción en su segunda fase, como complemento alternativo al ingreso de la familia beneficiaria ha implementado el desarrollo de un programa que permite generar cultura del ahorro en cuanto al hogar mediante el sistema de bancarización, para que las titulares inicien una vida crediticia, y las TMC son consignadas directamente a las cuentas de cada una de ellas entregándoles su respectiva tarjeta débito. Mediante el programa denominado mujeres ahorradoras el cual consiste en una idea de negocio que la mujer ahorradora desea llevar a cabo, y debe realizar una consignación mensual y al termino de 9 meses debe haber ahorrado el valor de $\$ 300.000$ pesos y el estado por intermedio del DPS les da un auxilio de $\$ 150.000$, igualmente en el tiempo que están ahorrando están en capacitación constante, sobre emprendimiento y la manera más fácil y eficaz de llevar su propia contabilidad, todo estos con miras a mejorar su calidad de vida, dicho ahorro servirá para ser invertido en el proyecto que la mujer ahorradora desea llevar a cabo, como son compra de equipos, maquinaria, enseres, inventario de materia prima, y al finalizar el ciclo se pudo establecer que hubo mujeres que ahorraron hasta $\$ 1.500 .000$ y el gobierno les otorgo $\$ 750.000$.

Mujeres ahorradoras fue un modelo alternativo a cerca de 850 familias en Bucaramanga, como complemento a ello el municipio de Bucaramanga, mediante el Instituto municipal de Empleo, Imebu, creo el programa Capital Semilla que permita aquellas madres beneficiarias del programa mujeres ahorradoras obtuvieran en la fase II un crédito con intereses blandos que 
permita a cerca de 150 hogares crear su fami-empresa, con créditos que oscilan entre $\$ 2.000 .000$ y $\$ 4.000 .000$ a 3 años con un año de gracia este programa es iniciativa del gobierno municipal como complemento alternativa a la proporción en los recursos que tiene el hogar.

\subsection{El Programa Más Familias en Acción en Colombia.}

A finales de los años noventa, la crisis económica y social que vivió el país produjo un incremento de la pobreza a niveles superiores a los presenciados en la década anterior. El estado colombiano se comprometió a poner en marcha programas para mitigar el impacto de la crisis en la población más pobre y favorecer la expansión de la infraestructura física y social de los sectores más desamparados del país. El plan Nacional de Desarrollo 19982002 "cambio para construir la paz" planteó la necesidad de implementar un programa de subsidios a la demanda de carácter nacional para asegurar la permanencia de los menores en el sistema escolar, En el eje de Reconstrucción del tejido social.

El gobierno nacional expidió los documentos CONPES 3075 y 3081 . El primero avaló el programa de subsidios condicionados (Familias en acción) como uno de los tres componentes de la Red de Apoyo Social, y autoriza al Gobierno Nacional a contratar un crédito externo para el financiamiento del programa Manos a la Obra (empleo en acción) (Acción social, hoy DPS, 2010:12). El segundo documento creó los programas de subsidios condicionados y capacitación laboral (jóvenes en acción) como parte de la RAS (red de apoyo social). Luego el documento CONPES 3144 instituyo el sistema social de Riesgo (SSR) como un instrumento de prevención y choque contra los efectos producidos por la crisis económica.

Familias en acción es en efecto, parte de una nueva generación de programas que relacionan de manera directa la ayuda monetaria con la acumulación de capital humano. Sus objetivos operativos son:

a) Reducir la inasistencia y deserción de los alumnos de educación primaria y secundaria.

b) Complementar el ingreso de las familias con niños menores de siete años en extrema pobreza para incrementar el gasto en alimentación.

c) Aumentar la atención de salud de los niños menores de siete años. 
d) Mejorar prácticas de cuidado de niños en aspectos tales como salud, nutrición, estimulación temprana y prevención de la violencia intrafamiliar.

El programa se fundamenta en una fórmula que combina la atención y el cuidado. La atención es "la acción del Estado para responder a las demandas de la población"; es ejercida por las administraciones territoriales (departamentos y municipios) a través de la prestación de los servicios de salud, educación y otros. El servicio es concebido como el efecto útil y visible de la función de atender. El otro componente es el cuidado, entendido como cambio del sujeto, creación de sí mismo, a través de la adopción de un forma de vida.

Los objetivos específicos de los programas de TMC varían, aunque tienen en común unas metas generales tales como mejorar los niveles educativos, combatir la deserción escolar y el trabajo infantil, apoyar la salud nutricional de los niños y en general las condiciones sanitarias de todos los beneficiarios, la mayoría de ellos buscan aliviar las necesidades inmediatas de las familias asegurándoles un ingreso mínimo, y romper con la transmisión de la pobreza intergeneracional y la desigualdad a través de la inversión en capital humano.

El programa familias en acción tienen varias particularidades generalizadas en las familias como son el énfasis en las familias en pobreza extrema con niños. Niñas y adolescentes, y en casi todos las mujeres son las titulares del programa. Para familias en acción, la familia se convierte entonces en una unidad fundamental de la política social, en la medida en que se la apoya para que sus integrantes tengan un mejor futuro desde el punto de vista del acceso a condiciones de bienestar. Para tal efecto las madres entran a jugar un rol relevante al asumir responsabilidades como eje de la actuación del grupo, bajo el supuesto de que las mujeres desempeñan un rol más efectivo dentro del grupo familiar que los hombres en la administración de recursos.

Operativamente el programa otorga dos tipos de subsidios uno nutricional, para familias con niños menores a 7 años, y uno escolar para familias con niños entre 7 y 18 años, el subsidio nutricional incluye actividades de 
vacunación, control de crecimiento y desarrollo, el subsidio escolar se adjudica a familias con niños y niñas que se encuentran estudiando desde primero de primaria hasta el grado once, con fin de incentivar la asistencia escolar, aumentar los años de escolaridad y reducir la deserción de la educación primaria y secundaria, la diferencia monetaria va a las familias si son vulnerables como nivel de sisben y la población desplazada por la violencia, los pagos son cada dos meses. Garantizando 6 pagos en el año.

Los montos son:

En el siguiente cuadro se exponen los auxilios condicionados con los que inicio el programa hasta diciembre de 2012.

\begin{tabular}{|c|c|c|}
\hline AUXILIO TMC & P.SISBEN & P. DESPLAZADA \\
\hline NUTRICION O A 7 AÑOS & $\$ 100.000$ & $\$ 100.000$ \\
\hline $\begin{array}{llll}\text { NUTRICION } & 7 & \text { A } & 11 \\
\text { AÑOS } & & & \end{array}$ & $\$ 40.000$ & $\$ 0$ \\
\hline PRIMARIA 1 A 5 & $\$ 0$ & $\$ 30.000$ \\
\hline $\begin{array}{lll}\text { SECUNDARIA } & 6- & 8 \\
\text { GRADO } & & \end{array}$ & $\$ 50.000$ & $\$ 60.000$ \\
\hline SECUNDARIA 9 Y 10 & $\$ 70.000$ & $\$ 60.000$ \\
\hline UNDECIMO & $\$ 80.000$ & $\$ 60.000$ \\
\hline
\end{tabular}

A partir del 1 de enero de 2013, empezó la fase III de Más familias en acción, y cambiaron los valores, convirtiéndola en ley de la republica $N^{\circ} 1532$ del 12 de junio de 2012, y como nuevo que los jóvenes con 18 años que estén cursando grado decimo el programa les garantiza el auxilio hasta el grado once, presentando el cumplimiento de sus compromisos de educación, dichos valores serán incrementados anualmente de acuerdo al índice de inflación.

El nuevo cuadro de auxilios condiciones es el siguiente: 


\begin{tabular}{|l|l|l|}
\hline AUXILIO TMC & P.SISBEN & P. DESPLAZADA \\
\hline NUTRICION O A 7 AÑOS & $\$ 120.000$ & $\$ 140.000$ \\
\hline PRIMARIA 1 A 5 & $\$ 20.000$ & $\$ 30.000$ \\
\hline $\begin{array}{l}\text { SECUNDARIA 6- } \\
\text { GRADO }\end{array}$ & $\$ 50.000$ & $\$ 70.000$ \\
\hline SECUNDARIA 9 Y 10 & $\$ 60.000$ & $\$ 90.000$ \\
\hline UNDECIMO & $\$ 90.000$ & $\$ 110.000$ \\
\hline
\end{tabular}

\subsection{Políticas de Acción en Bucaramanga.}

A comienzos del año 2008, en el gobierno del señor Alcalde Doctor Fernando Vargas Mendoza, fortaleció el programa de más familias en acción, creando para tal fin una oficina dotada de la más alta tecnología que permitió garantizar la atención a todos los beneficiarios, asignando un equipo humano y presupuestal que permitió realizar acompañamiento a la familia garantizando la verificación de compromisos en educación y salud, este programa lo complemento con la Red Unidos y el programa ReSA, se gestionó la ampliación de cobertura y crecimiento llegando en el 2010 a 19.270 familias inscritas y beneficiarias de los subsidios condicionados.

En el actual gobierno, del doctor Luis Francisco Bohórquez Pedraza un gobierno con una amplia política social, que permitió continuar con los convenios sociales con el DPS, articulando la política social con los diferentes secretarios de Despacho como son Desarrollo social, Salud y Educación en el actual gobierno se garantizó el acompañamiento a la familia y se fortaleció con campañas cívicas y culturales en programas como mujeres ahorradoras fase 1, cerca de 850 mujeres se beneficiaron de este convenio y se implementaron capacitaciones en creación de empresas, manualidades, artesanías entre otras. Es así como el municipio de Bucaramanga mediante los diversos programas sociales ayudan a fortalecer las iniciativas en cada uno de los hogares beneficiarios del programa Más familias en acción 


\section{CAPITULO II}

\section{Metodología de la Investigación}

La estrategia a corto plazo de las TMC se basa en transferencias en efectivo a las familias pobres con un efecto inmediato en la pobreza, según el nivel de la prestación y la eficacia de la estrategia de focalización. El efecto a largo plazo depende de la efectividad de las condiciones asociadas a las transferencias, tanto en términos de su aplicación y de su poder real en el fomento del capital humano y social. Las condicionalidades incluyen la asistencia obligatoria de los niños en la escuela, visitas obligatorias a los centros de salud, y la vigilancia de la nutrición y la inmunización. En general, estas condiciones se centran en los niños con el fin de romper la transmisión intergeneracional de la pobreza. Algunos especialistas sostienen que las condiciones no son necesarias ya que las transferencias de dinero ya se ocupan de las restricciones al crédito que enfrentan las familias pobres. Por lo tanto, el aumento de sus ingresos ayuda a mejorar los logros educativos, de salud y nutrición. Sin embargo, las condicionalidades también pueden tener otros efectos pertinentes. Por ejemplo, pueden ayudar a cambiar algunas de las características culturales que ponen en peligro las posibilidades de que los niños de familias pobres salgan de la pobreza. Por ejemplo, hay pruebas que las familias cuyos jefes trabajaron mientras estaban los niños tienen más probabilidades de enviar a sus hijos a trabajar. En casos como este, la condicionalidad podría inducir un cambio cultural que proteja a estos niños de una pronta entrada en el mercado de trabajo. En el mundo real, los programas de TMC específicos difieren en el diseño, implementación y objetivos.

Hay dos grandes grupos de argumentos para establecer condiciones para las transferencias en efectivo. El primer set se aplica si la inversión privada en capital humano de los niños se considera que es demasiado baja. El segundo conjunto se aplica si las condiciones de política económica muestran poco apoyo para su redistribución a menos que se cumpla con la condición de que el "buen comportamiento" de los pobres los hace 
merecedor a este tipo de ayudas. En el marco del primer grupo de argumentos, la inversión privada en capital humano puede ser "demasiado baja" en dos sentidos diferentes. En primer lugar, puede estar por debajo incluso del nivel óptimo privado para los niños individuales en cuestión de si los tomadores de decisiones de los hogares tienen creencias equivocadas acerca de la naturaleza del beneficio y derecho en la educación infantil y la salud o los posteriores retornos a estas inversiones. Por ejemplo, los padres pueden creer que las ganancias en la educación responden de manera menos elástica de lo que realmente hacen. En la práctica, hay algunas pruebas de esto desde los países en desarrollo. Entre 15 a 25 años de experiencia en México, los esperados retornos a la educación (calculados a partir de las preguntas formuladas a los entrevistados) son sustancialmente más bajos que los retornos obtenidos, especialmente entre los niños de padres con bajos niveles de educación (Attanasio y Kaufmann 2008). En la República Dominicana, los estudiantes de octavo grado estiman la tasa de retorno a la escuela secundaria como una mejora en programas similares teniendo en cuenta la tasa derivada de una encuesta de ingresos (Jensen 2006). Los padres también pueden percibir el futuro en mayor medida de lo que deberían, tal vez especialmente con respecto a los rendimientos de las inversiones en sus hijos -un caso de "altruismo incompleto." Una versión ligeramente diferente, pero igualmente plausible de este problema es un conflicto de intereses entre los propios padres y entre padres e hijos. Los objetivos de las madres pueden estar más estrechamente alineados con los de todos sus hijos o, tal vez, especialmente con los de sus hijas. Esa alineación a menudo se da como una justificación para dar la transferencia de dinero a la madre y no al padre, al igual que en la práctica común de la mayoría de los programas de TMC. En muchos países de Asia del Sur, la escolarización de las niñas está muy por detrás de la de los niños, a pesar de que los retornos a la educación femenina, tanto en los salarios, y en términos de salud infantil son al menos tan grandes como las de los hombres. Los bajos niveles de inversión en la escolarización de las niñas pueden ser racionales desde el punto de vista de los padres que están pensando en su propio bienestar (ya sea porque las niñas son más costosas en términos de dotes o porque los niños son más propensos a cuidar de sus padres ya que las niñas se mudan o crean hogares con sus maridos al casarse), pero son evidencia de un resultado socialmente ineficiente. 
Los procedimientos más utilizados para seleccionar poblaciones objeto dentro de un programa de TMC son aquellos de múltiples etapas.

La primera etapa consiste en la identificación de las unidades geográficas con los mayores índices de pobreza. Esto se evalúa generalmente sobre la base de los índices de marginalidad que pueden incluir variables de ingreso 0 necesidades básicas insatisfechas (NBI), y se construye a partir de fuentes de datos, tales como los censos de población, encuestas de hogares y los mapas de la pobreza. En el programa Tekoporâ en Paraguay, las comunidades más vulnerables son seleccionadas sobre la base de la puntuación de priorización geográfica que da una ponderación del $40 \%$ a las condiciones de pobreza de una localidad y un $60 \%$ a la presencia de necesidades básicas insatisfechas (De Janvry et al. 2006). En otros casos, los indicadores de necesidades básicas insatisfechas se utilizan para seleccionar las zonas rurales, y los ingresos y gastos se utilizan para las zonas urbanas (Schultz, 2004).

Después de la focalización geográfica, se seleccionan las unidades familiares en función de la definición que adopte cada programa, la mayoría de los programas utilizan los medios de prueba indirecta, ya sea a través de los índices multidimensionales de la calidad de vida, o fórmulas de predicción de ingresos que utilizan variables que se supone están estrechamente relacionados con los ingresos. También hay programas que implementan una prueba de medios directos, utilizando el nivel de ingresos reportados por las propias familias en encuestas ad hoc o censos realizados por los programas. En Brasil, esta información se recopila a nivel municipal mediante la aplicación del registro único para los programas sociales, conocidos como Cadúnico, a las familias que viven en la pobreza. Este procedimiento tiende a ser menos costoso y más rápido para los fines de la ampliación de la base de usuarios; pero también pueden ser más susceptibles a las fluctuaciones a corto plazo en los ingresos familiares (Macour, Schady \& Vakis, 2008). Las críticas a la forma en que este método se aplica en Brasil incluyen el potencial para un mayor error de inclusión según la comparación de los informes de ingresos de la familia con otros más formales o institucionales.

Un desafío permanente para los programas de TMC ha sido definir los criterios de salida o entrada a estos programas, mecanismos que dependen de sus objetivos de mediano y largo plazo. En, la práctica, se hace más énfasis en la definición de reglas para salir; es decir, buscan asegurar a las familias que no van a necesitar ayuda social o asistencia en el futuro. A 
menudo, esto se ha visto influido más por limitaciones presupuestarias o consideraciones políticas (acortando la longitud de la estancia para aumentar el número bruto de las personas que pasan por el programa), que por los objetivos del programa (De Janvry et al., 2006).

Los criterios de salida más utilizados en los programas de TMC son así de simples: el usuario deja de recibir los subsidios cuando sus miembros ya no reúnen las condiciones de elegibilidad. En otras palabras, las familias dejan el programa cuando sus hijos pasan los límites de edad correspondientes, lo que significa que las familias se pueden dejar en una situación similar o peor de vulnerabilidad que antes de la intervención (Rawling, 2004). Otro método frecuente es definir las reglas de salida basadas en un número máximo de años en el programa. Por ejemplo, en el Targeted Programa de Transferencias Monetarias Condicionadas de Trinidad y Tobago, el límite es de dos años; el límite para las subvenciones condicionadas sobre Asistencia Escolar en Bogotá es de entre dos y tres años, dependiendo del tipo de subsidio recibido; mientras que en el Brasil el Programa de Erradicación (PETI) el límite es de cuatro años. En el caso de la Red de Protección Social (RPS) y el Sistema de Respuesta a las Crisis (SAC) de Nicaragua, el plazo de vencimiento del préstamo que se utilizó para financiar éstos programas limitan automáticamente la duración de la estancia, sin ningún tipo de transición a un nuevo esquema de protección. En otros casos, los objetivos del programa se tienen en cuenta, explícitamente en el diseño de estrategias de graduación. Ejemplos como Oportunidades en México, Bolsa Familia en Brasil, PATH en Jamaica, y Solidaridad en la República Dominicana, especifican los períodos de estancia con la posibilidad de re-certificación, mediante la definición de los umbrales de ingresos para la graduación del programa. Si las familias no pueden pasar estos umbrales se debe mantener su condición de usuarios del programa. Esquemas de este tipo tienden a priorizar aspectos de corto plazo para reducir la pobreza y la dependencia de los usuarios, lo que socava el largo plazo la capacidad humana y objetivos de promoción social de cada programa.

\subsection{Justificación}

Existe gran variedad de programas sociales a nivel Nacional que ayudan en diferentes líneas a los hogares vulnerables de la población colombiana, tan es así que hoy en día el departamento de la Prosperidad Social "DPS logro 
convertir estos programas sociales en una política de social mediante una ley de la República; una de las metas de éste gobierno es quitar el estigma que se venía manejando de ser programas netamente asistenciales y convertirlos en programas condicionados que logran evitar la deserción escolar, garantizando calidad educativa y permitiendo que con estos recursos los jóvenes puedan desplazarse, alimentarse y vestirse. En el componente de salud permite que la madre pueda tener los recursos suficientes a controles de crecimiento y desarrollo y contribuir en una buena nutrición.

También analizaremos la inversión de estos subsidios y su impacto económico en cada hogar. Este programa va de la mano con la red Unidos que permite mediante el acompañamiento de los Cogestores a erradicar la pobreza extrema permitiendo acceder a toda la oferta institucional que brinda el Gobierno Nacional y Municipal.

Como complemento de éste programa se han diseñado dos programas alternos como son Jóvenes en Acción, que permite a aquellos estudiantes que terminan su ciclo académico del programa Más Familias en Acción puedan acceder a una carrera técnica en el SENA o en otra institución calificada de Educación Superior, recibiendo un subsidio durante su estancia académica y el otro programa denominado Mujeres Ahorradoras destinado a aquellos hogares que hacen esfuerzo por ahorrar permite recibir un incentivo adicional que será invertido en un capital semilla a los hogares cumpla su objetivo.

\subsection{Marco Teórico}

Es importante aclarar que en la investigación cualitativa, es decir " la teoría fundamentada es una de las tradiciones de investigación cualitativa, la cual se define como aquella que permite formular una teoría que se encuentra subyacente en la información obtenida en el campo empírico" (hernandez 2010) por eso en la presente investigación se emplea técnicas cualitativa como: la observación, las entrevistas a profundidad, encuestas, entre otros.

Hay dos grandes grupos de argumentos para establecer condiciones para las transferencias en efectivo. El primer set se aplica si la inversión privada en capital humano de los niños se considera que es demasiado baja. El segundo conjunto se aplica si las condiciones de política económica muestran poco apoyo para su redistribución a menos que se cumpla con la condición de que el "buen comportamiento" de los pobres los hace merecedor a este tipo de ayudas. En el marco del primer grupo de 
argumentos, la inversión privada en capital humano puede ser "demasiado baja" en dos sentidos diferentes. En primer lugar, puede estar por debajo incluso del nivel óptimo privado para los niños individuales en cuestión de si los tomadores de decisiones de los hogares tienen creencias equivocadas acerca de la naturaleza del beneficio y derecho en la educación infantil y la salud o los posteriores retornos a estas inversiones. Por ejemplo, los padres pueden creer que las ganancias en la educación responden de manera menos elástica de lo que realmente hacen. En la práctica, hay algunas pruebas de esto desde los países en desarrollo. Entre 15 a 25 años de experiencia en México, los esperados retornos a la educación (calculados a partir de las preguntas formuladas a los entrevistados) son sustancialmente más bajos que los retornos obtenidos, especialmente entre los niños de padres con bajos niveles de educación (Attanasio y Kaufmann 2008). En la República Dominicana, los estudiantes de octavo grado estiman la tasa de retorno a la escuela secundaria como una mejora en programas similares teniendo en cuenta la tasa derivada de una encuesta de ingresos (Jensen 2006). Los padres también pueden percibir el futuro en mayor medida de lo que deberían, tal vez especialmente con respecto a los rendimientos de las inversiones en sus hijos -un caso de "altruismo incompleto." Una versión ligeramente diferente, pero igualmente plausible de este problema es un conflicto de intereses entre los propios padres y entre padres e hijos. Los objetivos de las madres pueden estar más estrechamente alineados con los de todos sus hijos o, tal vez, especialmente con los de sus hijas. Esa alineación a menudo se da como una justificación para dar la transferencia de dinero a la madre y no al padre, al igual que en la práctica común de la mayoría de los programas de TMC. En muchos países de Asia del Sur, la escolarización de las niñas está muy por detrás de la de los niños, a pesar de que los retornos a la educación femenina, tanto en los salarios, y en términos de salud infantil son al menos tan grandes como las de los hombres. Los bajos niveles de inversión en la escolarización de las niñas pueden ser racionales desde el punto de vista de los padres que están pensando en su propio bienestar (ya sea porque las niñas son más costosas en términos de dotes o porque los niños son más propensos a cuidar de sus padres ya que las niñas se mudan o crean hogares con sus maridos al casarse), pero son evidencia de un resultado socialmente ineficiente.

Los procedimientos más utilizados para seleccionar poblaciones objeto dentro de un programa de TMC son aquellos de múltiples etapas. 
La primera etapa consiste en la identificación de las unidades geográficas con los mayores índices de pobreza. Esto se evalúa generalmente sobre la base de los índices de marginalidad que pueden incluir variables de ingreso 0 necesidades básicas insatisfechas (NBI), y se construye a partir de fuentes de datos, tales como los censos de población, encuestas de hogares y los mapas de la pobreza. En el programa Tekoporâ en Paraguay, las comunidades más vulnerables son seleccionadas sobre la base de la puntuación de priorización geográfica que da una ponderación del $40 \%$ a las condiciones de pobreza de una localidad y un $60 \%$ a la presencia de necesidades básicas insatisfechas (De Janvry et al. 2006). En otros casos, los indicadores de necesidades básicas insatisfechas se utilizan para seleccionar las zonas rurales, y los ingresos y gastos se utilizan para las zonas urbanas (Schultz, 2004).

Después de la focalización geográfica, se seleccionan las unidades familiares en función de la definición que adopte cada programa, la mayoría de los programas utilizan los medios de prueba indirecta, ya sea a través de los índices multidimensionales de la calidad de vida, o fórmulas de predicción de ingresos que utilizan variables que se supone están estrechamente relacionados con los ingresos. También hay programas que implementan una prueba de medios directos, utilizando el nivel de ingresos reportados por las propias familias en encuestas ad hoc o censos realizados por los programas. En Brasil, esta información se recopila a nivel municipal mediante la aplicación del registro único para los programas sociales, conocidos como CAD Único, a las familias que viven en la pobreza. Este procedimiento tiende a ser menos costoso y más rápido para los fines de la ampliación de la base de usuarios; pero también pueden ser más susceptibles a las fluctuaciones a corto plazo en los ingresos familiares (Macour, Schady \& Vakis, 2008). Las críticas a la forma en que este método se aplica en Brasil incluyen el potencial para un mayor error de inclusión según la comparación de los informes de ingresos de la familia con otros más formales o institucionales.

En el desarrollo de éste trabajo utilizaremos la encuesta directa a la beneficiaria plenamente identificada por el programa en la gran mayoría madre líder con experiencia y antigüedad que nos permite ver el alcance del subsidio en el hogar, la conformación de su núcleo familiar, el ingreso como tal y analizaremos una variable, cual es la inversión y el ahorro. 


\subsubsection{Preguntas de la Investigación.}

¿Qué uso le da la familia a las transferencias condicionadas del programa Mas Familias en acción en el Municipio de Bucaramanga?

¿Qué capacidad de ahorro tiene cada hogar?

¿Qué manejo le dan las familias a la cuente de ahorro del sistema de Bancarización de la TMC del Banco Agrario?

\subsubsection{Objetivo.}

Conocer las actuales condiciones económicas de cada familia que reciben las TMC del Programa Más familias en acción de Bucaramanga y analizar el impacto de los subsidios en el sistema de Bancarización.

\subsection{Hipótesis}

Revisando lo expresado por el autor Hernández (2010), en los estudios cualitativos no se prueba hipótesis, sino que estas se van generándolo durante el proceso y se perfeccionan durante el proceso, a medida que se van recibiendo datos que permitan mostrar un estudio, sin embargo la presente investigación apunta por medio de la observación a comprobar : Que uso le da la familia a los ingresos provenientes de la TMC, que manejo le dan a la cuenta de ahorros donde se deposita el subsidio y que participación tiene en el ingreso de cada hogar la TMC del programa Mas Familias en Acción.

\subsection{Métodos Utilizados}

El análisis cualitativo de las estrategias de ahorro y crédito de las familias beneficiarias del programa Familias en Acción, que se presenta en este documento, se sustenta en la información recogida a partir de las entrevistas semi-estructuradas a madres beneficiarias del programa en cinco comunas donde está representada el $90 \%$ de las madres y un $10 \%$ representados de la parte rural y otras comunas donde no hay mayor numero de beneficiarias.

La entrevista se dividió en siete secciones, donde se reflejaron aspectos como: Datos generales de la beneficiaria, aspectos financieros, aspectos de 
ahorro ingreso y gastos, shocks 0 acontecimientos y estrategias, ventajas de los mecanismos de pagos electrónicos y aspectos de temas como la bancarización y líneas de crédito usadas con entidades financieras.

En la sección introductoria se explica las madres beneficiarias el propósito general de la entrevista, los alcances de las mismas, la confidencialidad de sus respuestas y opiniones y se les solicita permiso para gravar la entrevista y firmarla, de igual forma se le explica que es un estudio una investigación para ser presentada como proyecto académico y que tendrá la reserva del caso.

El Enlace Municipal, realiza la planeación de las entrevistas, selecciona un número de madres líderes y beneficiarias, invitándolas a la oficina del enlace, ofrece refrigerio explica el alcance de la misma y ofrece transporte para garantizar la asistencia del universo a entrevistar.

La sección que se enfoca con el componente financiero, que se divide en ahorro y crédito, con este propósito se quiere obtener información acerca de los mecanismos formales e informales que actualmente utilizan las beneficiarias para suavizar las sendas de consumo y de ingreso.

La sección que habla de Shocks y estrategias de que se habla en la entrevista, se enfoca como su nombre lo indica, en capturar los mecanismos que utilizan las madres beneficiarias del programa para enfrentar los acontecimientos y las estrategias a las que recurren para planificar eventos previstos.

Finalmente las secciones cinco, seis y siete tiene como propósito fundamental, recoger las percepciones que las madres tienen acerca de las diferentes medios de pago que tiene el programa, modalidades de ahorro entre otras, este proceso busca conocer la cultura de ahorro, el manejo de cuentas electrónicas, bancarización y como cada familia distribuye sus ingresos.

Todas las entrevistas fueron realizadas con autorización del Enlace Municipal, citadas por el y ayudadas a realizar por su equipo de apoyo en la oficina del enlace, durante los meses de Octubre y Noviembre de 2.014, cada una con duración de 20 a 25 minutos. 


\subsection{La Encuesta}

\section{ENCUESTA A MADRES BENEFICIARIAS DEL PROGRAMA MÁS FAMILIAS EN ACCION}
LUGAR DE LA ENCUESTA: Municipio Bucaramanga Oficina del Enlace Municipal

FECHA:

BOMBRE DE LA TITULAR:

IDENTIFICACION:

DIRECCION:

COMUNA:

BARRIO:

1. TIEMPO EN LA CIUDAD:

2. LUGAR DE NACIMIENTO:

3 .DEPARTAMENTO:

4. EDAD:

5. ESTADO CIVIL:

6. No. DE HIJOS:

7. EDADES AÑOS.:

8. NOMBRE DEL CONYUGE:

9. EDAD:

10. PROFESION:
17 Noviembre de 2014

Marisol Prada Gutiérrez

63.344.193 De Bucaramanga

Cra 13 No. $63-05$

Pablon

15 Años

Municipio De Gamarra

$\underline{\text { Cesar }}$

46 Años

Casada

$\underline{04}$

$\underline{25,23,18,11 \text { Años }}$

José Martin López

46 Años

$\underline{\text { Auxiliar De Construcciones }}$ 
11. INGRESOS:

$\$ 610.000$

12. INGRESO NETO:

$\$ 610.0000$

13. ACTIVIDAD ECONOMICA:

Servicio Domestico

14. INGRESO NETO:

$\$ 450.0000$

15. TRABAJA OTRO MIEMBRO DE LA FAMILIA:

No.

16. INGRESO TOTAL DEL FAMILIA:

$\$ 1.060 .000$

17. GASTOS FAMILIARES:

$\$ 920.000$

18. AHORO PROMEDIO POR MES:

$\$ 70.000$

19. ¿QUE FIN TIENE EL AHORRO?:

$\underline{\text { Viajar }}$

20. CUANTO TIEMPO DURA AHORRANDO:

$\underline{24 \text { Meses }}$

21. HA UTILIZADO LOS SERVICIOS DE EMPEÑO:

$\underline{\text { Si }}$

22. QUE ARTÍCULO UTILIZA PARA ESTE FIN:

Cadena De Oro $\mathrm{O}$

Licuadora

23 .MONTO DEL EMPEÑO:

$\$ 50.0000-\$ 70.000$

24. FRECUENCIA DE UTILIZACION:

$\underline{3 \text { Veces al año }}$

25. UTILIZA LA MODALIDAD DE PRESTAMO GOTA A GOTA:

SI

26. MONTO DE LA SOLICITUD EN ESTA MODALIDAD:

$\$ 60.000$

27. INTERES QUE MANEJA AL DIARIO:

$\underline{10 \% \text { mensual }}$

28. TIEMPO DEMORA EN PAGAR DICHO PRESTAMO (DIAS): 15 Días 29. FINALIDAD DEL PRESTAMO: $\quad$ Pago De Servicios O Transporte 
30. CUANTOS SUBSIDIOS RECIBE DEL PROGRAMA MAS FAMILIAS EN ACCION BIMENSUALMENTE:

31. COMO RECIBE ESTE SUBSIDIO: Mediante Giro a mi Cuenta De Ahorros

32. HA UTILIZADO ENTIDADES FINANCIERAS PARA AHORRAR: $\underline{\text { Si }}$

33. ¿CUAL?:

Coomultrasan

34. ¿A QUE DESTINA EL SUBSIDIO QUERECIBE DEL PROGRAMA MAS FAMILIAS EN ACCIÓN?: Compra De Uniformes, Textos Y Transporte Escolar.

35. HA UTILIZADO CREDITO CON ALGUNA ENTIDAD FINANCIERA: $\underline{\mathrm{Si}}$

36. ¿CUAL?:

Coomultrasan

37. MOTIVO DEL CREDITO:

Compra De Materiales

38. ¿MONTO SOLICITADO?

$\$ 1.000 .000$

39. ¿EL SUBSIDIO DE MAS FAMILIAS EN ACCIÓN EN QUE LE HA CONTRIBUIDO EN SU HOGAR?

Es una ayuda que me ha permitido garantizar el envió de mis hijos al colegio, gracias a ello durante el mes de noviembre. Diciembre y Enero, ahorro ese recurso de los útiles escolares. Y los meses de Febrero y marzo compro uniformes, $y$ el resto de meses lo destino para el transporte escolar, es un subsidio que no se puede ahorrar, se debe invertir en los hijos.

4.0 ¿ALGUNO DE SUS HIJOS MENOR DE EDAD REALIZA ALGUNA ACTIVIDAD LABORAL NO FORMAL?: Sí, generalmente en horas de la tarde vende minutos en una estación de bus y los fines de semana servicio de domicilios en un restaurante 


\section{CAPITULO III}

\section{Desarrollo de la Encuesta y Trabajo de Campo con las Familias Beneficiarias.}

En el presente capitulo doy a conocer los resultados de la encuesta que se uso para poder analizar el comportamiento de los subsidio, su uso, y la forma como incide en los hogares. También analizaremos la capacidad de ahorro que tienen los hogares beneficiarios que tienen el subsidio en cada una de las comunas donde tienen mayor incidencia determinada población. Cada resultado se encuentra sustentado.

\subsection{Resultado de la Encuesta}

Cuadro No. 1. Caracterización de las entrevistas realizadas en cada comuna.

\begin{tabular}{|l|c|l|l|c|}
\hline COMUNA & $\begin{array}{l}\text { NUMERO DE } \\
\text { ENTREVISTAS }\end{array}$ & $\begin{array}{l}\text { FECHA DE } \\
\text { REALIZACION }\end{array}$ & $\begin{array}{l}\text { LUGAR DE } \\
\text { REALIZACION }\end{array}$ & $\begin{array}{l}\text { NUMERO DE } \\
\text { MADRES } \\
\text { LIDERES }\end{array}$ \\
\hline COMUNA 1 & 6 & Octubre de 2014 & $\begin{array}{l}\text { Oficina del } \\
\text { enlace Municipal }\end{array}$ & 0 \\
\hline COMUNA 2 & 11 & Octubre de 2014 & $\begin{array}{l}\text { Oficina enlace } \\
\text { municipal }\end{array}$ & 4 \\
\hline COMUNA 4 & 13 & Octubre de 2014 & $\begin{array}{l}\text { Oficina Enlace } \\
\text { Municipal }\end{array}$ & 9 \\
\hline COMUNA 9 & 20 & $\begin{array}{l}\text { Noviembre de } \\
2014\end{array}$ & $\begin{array}{l}\text { Oficina Enlace } \\
\text { Municipal }\end{array}$ & 8 \\
\hline COMUNA 14 & 14 & $\begin{array}{l}\text { Noviembre de } \\
2.104\end{array}$ & $\begin{array}{l}\text { Oficina Enlace } \\
\text { Municipal }\end{array}$ & 4 \\
\hline $\begin{array}{l}\text { OTRAS } \\
\text { COMUNAS }\end{array}$ & 09 & $\begin{array}{l}\text { Noviembre de } \\
2.014\end{array}$ & $\begin{array}{l}\text { Oficina Enlace } \\
\text { Municipal }\end{array}$ \\
\hline TOTAL & $\mathbf{7 3}$ & & & 30 \\
\hline
\end{tabular}

Fuente: Cálculos propios a partir de entrevistas a madres titulares.

Las grabaciones fueron transcritas y junto con las notas recogidas en las entrevistas, se construyó una base de datos en Excel, donde se incluyeron todas las preguntas en una hoja para cada comuna. 
Entre las madres entrevistadas encontramos 30 madres líderes, 20 madres en situación de desplazamiento y ninguna madre perteneciente a comunidades indígenas.

Antes de presentar los resultados de las entrevistas se describen, a continuación, algunas características de las madres beneficiarias entrevistadas.

\section{Características generales de las madres entrevistadas}

Las madres entrevistadas pertenecen al programa Familias en Acción, en promedio, hace 26,4 meses, en un rango que varía desde un mes hasta 7 años (Cuadro 2).

Cuadro 2. Características generales madres entrevistadas

\begin{tabular}{|l|c|c|}
\hline Comuna & $\begin{array}{l}\text { Tiempo } \\
\text { promedio de } \\
\text { permanencia en } \\
\text { FA (Meses) }\end{array}$ & $\begin{array}{l}\text { Número promedio de hijos inscritos } \\
\text { actualmente en FA }\end{array}$ \\
\hline COMUNA 1 & 22,0 & 1,83 \\
\hline COMUNA 2 & 25,3 & 1,33 \\
\hline COMUNA 4 & 19,5 & 2,07 \\
\hline COMUNA 9 & 20,6 & 2,23 \\
\hline COMUNA 14 & 32,8 & 2,45 \\
\hline $\begin{array}{l}\text { OTRAS } \\
\text { COMUNAS }\end{array}$ & 33,3 & 2,75 \\
\hline TOTAL & $\mathbf{2 6 , 4}$ & $\mathbf{2 , 2 0}$ \\
\hline
\end{tabular}

Fuente: Cálculos propios a partir de entrevistas a madres titulares

En promedio, estas madres tienen 2,2 hijos inscritos el programa (Cuadro 2). Aunque varias de las madres entrevistadas tienen como lugar de nacimiento el mismo lugar de residencia actual, más de la mitad de ellas (35) proviene de otros municipios del departamento y otras muy pocas de otras ciudades fuera del departamento (Cuadro 3). 


\section{Cuadro 3. Procedencia de las madres entrevistadas (porcentajes por comunas en paréntesis)}

\begin{tabular}{|c|c|c|c|c|}
\hline \multirow[b]{2}{*}{ Comuna } & \multirow{2}{*}{$\begin{array}{l}\text { Numero de } \\
\text { entrevistas }\end{array}$} & \multicolumn{3}{|c|}{ Numero de madres por lugar de nacimiento } \\
\hline & & $\begin{array}{c}\text { Municipio de la } \\
\text { entrevista }\end{array}$ & $\begin{array}{l}\text { Otro municipio } \\
\text { en el mismo } \\
\text { departamento }\end{array}$ & $\begin{array}{c}\text { Otro } \\
\text { departamento } \\
\text { del país }\end{array}$ \\
\hline Comuna 1 & 6 & $2(33 \%)$ & $2(33 \%)$ & $2(33 \%)$ \\
\hline Comuna 2 & 9 & $7(78 \%)$ & $1(11 \%)$ & $1(11 \%)$ \\
\hline Comuna 4 & 14 & $9(64 \%)$ & $3(21 \%)$ & $2(14 \%)$ \\
\hline Comuna 9 & 13 & $10(77 \%)$ & $1(8 \%)$ & $2(15 \%)$ \\
\hline Comuna 14 & 11 & $5(45 \%)$ & $2(18 \%)$ & $4(36 \%)$ \\
\hline $\begin{array}{l}\text { Otras } \\
\text { comunas }\end{array}$ & 20 & $5(25 \%)$ & $10(50 \%)$ & $5(25 \%)$ \\
\hline Total & & $38(52 \%)$ & $19(26 \%)$ & $16(22 \%)$ \\
\hline
\end{tabular}

Fuente: Cálculos propios a partir de entrevistas a madres titulares

En promedio, las madres entrevistadas han vivido en el lugar de la entrevista más de 20 años, aunque este promedio varía entre ciudades en un rango que oscila entre aproximadamente 14 y 34 años (Cuadro 4).

\section{Cuadro 4. Años de residencia en la comuna de la entrevista}

\begin{tabular}{|l|c|c|}
\hline Comuna & Tiempo de residencia en la comuna de la entrevista & Numero de observaciones \\
\hline Comuna 1 & 18,0 & 5 \\
\hline Comuna 2 & 33,5 & 8 \\
\hline Comuna 4 & 24,3 & 9 \\
\hline Comuna 9 & 23,7 & 7 \\
\hline Comuna 14 & 14,4 & 17 \\
\hline Otras comunas & 19,2 & $\mathbf{5 7}$ \\
\hline Total & $\mathbf{2 3 , 1}$ & \\
\hline
\end{tabular}

Fuente: Cálculos propios a partir de entrevistas a madres titulares 
El tamaño del hogar de las madres entrevistadas presenta amplias variaciones entre comunas, siendo las comunas localizadas en el norte del municipio y el occidente del mismo, de otra parte la gran mayoría de ellas reside en zonas de alto riesgo.

\section{Cuadro 5. Tamaño promedio del hogar}

\begin{tabular}{|l|c|c|}
\hline Comuna & $\begin{array}{c}\text { Tamaño promedio del hogar } \\
\text { (número de miembros del } \\
\text { hogar) }\end{array}$ & $\begin{array}{c}\text { Promedio de personas que } \\
\text { trabajan en el hogar (número de } \\
\text { miembros) }\end{array}$ \\
\hline Comuna 1 & 5,3 & 2,0 \\
\hline Comuna 2 & 3,9 & 1,3 \\
\hline Comuna 4 & 5,7 & 1,0 \\
\hline Comuna 9 & 6,6 & 1,9 \\
\hline Comuna 14 & 5,8 & 1,6 \\
\hline Otras comunas & 6,3 & $\mathbf{1 , 8}$ \\
\hline Total & $\mathbf{5 , 8}$ & \\
\hline
\end{tabular}

Fuente: Cálculos propios a partir de entrevistas a madres titulares

La gran mayoría de las posiciones ocupacionales reportadas por las madres, para ella y su cónyuge, son trabajador independiente y trabajador de negocio propio (Cuadro 6). Entre las ocupaciones mencionadas en la categoría trabajador independiente se resaltan jornaleros, albañiles por días, conductores de moto taxi, carpinteros y ebanistas, oficios varios por días, empleadas domésticas, auxiliares de zapatería, guarnecedoras, vigilantes. 
Cuadro 6. Posición ocupacional de la madre beneficiaria y su cónyuge (porcentajes por comuna en paréntesis)

\begin{tabular}{|c|c|c|c|c|c|c|}
\hline \multirow{2}{*}{\multicolumn{2}{|c|}{ Comuna }} & \multicolumn{5}{|c|}{ Posición ocupacional } \\
\hline & & \multirow{3}{*}{$\begin{array}{c}\text { Empleado } \\
\text { gobierno } \\
--- \\
---\end{array}$} & \multirow{3}{*}{$\begin{array}{c}\begin{array}{c}\text { Empleado } \\
\text { privado }\end{array} \\
1(17 \%) \\
---\end{array}$} & \multirow{3}{*}{$\begin{array}{c}\begin{array}{c}\text { Trabajador } \\
\text { independiente }\end{array} \\
3(50 \%) \\
4(100 \%)\end{array}$} & \multirow{3}{*}{\begin{tabular}{|c|}
$\begin{array}{c}\text { Negocio } \\
\text { propio }\end{array}$ \\
--- \\
---
\end{tabular}} & \multirow{3}{*}{$\begin{array}{l}\text { Hogar } \\
2 \\
(33 \%) \\
\quad---\end{array}$} \\
\hline \multirow[t]{2}{*}{ Comuna 1} & Beneficiario & & & & & \\
\hline & Cónyuge & & & & & \\
\hline \multirow[t]{2}{*}{ Comuna 2} & Beneficiario & \multirow{2}{*}{--- } & \multirow{2}{*}{1 (17\%) } & \multirow{2}{*}{$\begin{array}{c}1(11 \%) \\
4(67 \%)\end{array}$} & \multirow{2}{*}{$\begin{array}{c}3(33 \%) \\
1(17 \%)\end{array}$} & \multirow{2}{*}{$\begin{array}{l}5 \\
(56 \%) \\
---\end{array}$} \\
\hline & Cónyuge & & & & & \\
\hline \multirow[t]{2}{*}{ Comuna 4} & Beneficiario & \multirow{2}{*}{$\begin{array}{l}1(7 \%) \\
---\end{array}$} & \multirow{2}{*}{$\begin{array}{l}-- \\
---\end{array}$} & \multirow{2}{*}{$\begin{array}{l}6(43 \%) \\
5(83 \%)\end{array}$} & \multirow{2}{*}{$\begin{array}{l}4(29 \%) \\
1(17 \%)\end{array}$} & \multirow{2}{*}{$\begin{array}{l}3 \\
(21 \%) \\
\quad---\end{array}$} \\
\hline & Cónyuge & & & & & \\
\hline \multirow[t]{2}{*}{ Comuna 9} & Beneficiario & \multirow{2}{*}{$\begin{array}{l}-- \\
1(13 \%)\end{array}$} & \multirow{2}{*}{$\begin{array}{c}1(9 \%) \\
---\end{array}$} & \multirow{2}{*}{$\begin{array}{l}2(18 \%) \\
5(63 \%)\end{array}$} & \multirow{2}{*}{$\begin{array}{l}2(18 \%) \\
2(25 \%)\end{array}$} & \multirow{2}{*}{$\begin{array}{l}6 \\
(55 \%) \\
\quad---\end{array}$} \\
\hline & Cónyuge & & & & & \\
\hline \multirow{2}{*}{$\begin{array}{l}\text { Comuna } \\
14\end{array}$} & Beneficiario & \multirow{2}{*}{$\begin{array}{l}-- \\
---\end{array}$} & \multirow{2}{*}{$1(10 \%)$} & \multirow{2}{*}{$\begin{array}{l}5(45 \%) \\
3(30 \%)\end{array}$} & \multirow{2}{*}{$\begin{array}{l}2(18 \%) \\
6(60 \%)\end{array}$} & \multirow{2}{*}{$\begin{array}{l}4 \\
(36 \%) \\
---\end{array}$} \\
\hline & Cónyuge & & & & & \\
\hline \multirow{2}{*}{$\begin{array}{l}\text { Otras } \\
\text { comunas }\end{array}$} & Beneficiario & \multirow{2}{*}{$\begin{array}{l}-- \\
---\end{array}$} & --- & $4(20 \%)$ & $9(45 \%)$ & \multirow{2}{*}{$\begin{array}{l}7 \\
(35 \%)\end{array}$} \\
\hline & cónyuge & & --- & $9(90 \%)$ & $1(10 \%)$ & \\
\hline Total & Beneficiario & $1(1 \%)$ & $2(3 \%)$ & $21(30 \%)$ & $20(28 \%)$ & 27 \\
\hline & cónyuge & $1(2 \%)$ & 2 (5\%) & 30 (68\%) & $11(25 \%)$ & --- \\
\hline
\end{tabular}

Fuente: Cálculos propios a partir de entrevistas a madres titulares.

A diferencia del trabajador independiente, en la categoría negocio propio se incluyen aquellas personas que combinan la mano de obra propia con algún tipo de inversión en equipos, insumos, etc. Los negocios propios de las madres beneficiarias y sus cónyuges que se reportan con mayor frecuencia son pequeños negocios -algunos de ellos ambulantes o a domicilio- de venta de alimentos (dulces, empanadas, arepas, agua, hielo), minutos de celular, artesanías, ropa y cosméticos, gasolina (en la comuna 14) y alquiler de lavadoras.

Finalmente, los hogares de las madres entrevistadas que trabajan reciben el salario mínimo, y con extras reciben máximo $\$ 720.000$ al mes, de igual forma las que no tiene trabajo estable pero realizan una actividad obtiene un ingreso no superior a los $\$ 320$. 
Cuadro 7. Ingresos y gastos mensuales del hogar reportados en las entrevistas

\begin{tabular}{|l|c|c|c|c|}
\hline Comuna & $\begin{array}{c}\text { Ingresos } \\
\text { mensuales } \\
\mathbf{( \$ \text { mes} )}\end{array}$ & $\begin{array}{c}\text { Numero de } \\
\text { madres que } \\
\text { respondieron }\end{array}$ & $\begin{array}{c}\text { Gastos } \\
\text { mensuales } \\
\mathbf{( \$ \text { mes} )}\end{array}$ & $\begin{array}{c}\text { Numero de } \\
\text { madres que } \\
\text { respondieron }\end{array}$ \\
\hline Comuna 1 & 820.000 & 5 & 790.000 & 6 \\
\hline Comuna2 & 760.000 & 8 & 750.200 & 9 \\
\hline Comuna 4 & 730.520 & 14 & 690.500 & 12 \\
\hline Comuna 9 & 685.300 & 12 & 655.500 & 14 \\
\hline Comuna 14 & 920.000 & 11 & 800.370 & 11 \\
\hline $\begin{array}{l}\text { Otras } \\
\text { comunas }\end{array}$ & 720.560 & 20 & 710.000 & 20 \\
\hline Total & $\mathbf{7 7 2 . 7 3 0}$ & $\mathbf{7 1}$ & $\mathbf{7 3 2 . 7 6 2}$ & $\mathbf{7 2}$ \\
\hline
\end{tabular}

Fuente: Cálculos propios a partir de entrevistas a madres titulares

Esta rápida caracterización muestra las condiciones de pobreza de las familias beneficiarias desde diferentes dimensiones

\section{Resultados}

Este capítulo de resultados se subdivide en cuatro secciones: las dos primeras analizan aspectos financieros del hogar: ahorro y crédito, la tercera, shocks y estrategias y la cuarta, la bancarización como estrategia para la suavización del consumo y del ingreso: ventajas y desventajas.

\section{Ahorros}

Las madres entrevistadas revelaron diferentes mecanismos de ahorro asociados, principalmente, con ahorro no formal. Solamente cuatro de las madres entrevistadas reportaron hacer uso del servicio de depósitos en alguna entidad financiera, mientras que 27 de 73 madres manifestaron no ahorrar bajo ningún mecanismo formal ó informal (Cuadro 8). 


\section{Cuadro 8. Formas de ahorro de las madres titulares (porcentajes por comunas en paréntesis)}

\begin{tabular}{|c|c|c|c|c|c|c|c|}
\hline \multirow{2}{*}{ Comuna } & \multicolumn{7}{|c|}{ Como ahora ¿número de madres? } \\
\hline & $\begin{array}{c}\text { Entidad } \\
\text { financiera } \\
\text { (depósito } \\
\text { s) }\end{array}$ & $\begin{array}{c}\text { Alcancí } \\
\text { a o } \\
\text { efectivo }\end{array}$ & $\begin{array}{c}\text { Cadena } \\
\text { s, } \\
\text { fondos, } \\
\text { tandas }\end{array}$ & $\begin{array}{c}\text { Materias } \\
\text { de } \\
\text { construcci } \\
\text { ón }\end{array}$ & $\begin{array}{c}\text { Animales } \\
\text { doméstico } \\
s\end{array}$ & Otro & $\begin{array}{c}\text { No } \\
\text { ahorra }\end{array}$ \\
\hline Comuna 1 & $1(17 \%)$ & $1(17 \%)$ & --- & --- & --- & --- & $4(67 \%)$ \\
\hline Comuna 2 & $2(13 \%)$ & $4(27 \%)$ & $5(33 \%)$ & $1(7 \%)$ & $1(7 \%)$ & --- & $2(13 \%)$ \\
\hline Comuna 4 & $1(7 \%)$ & $6(43 \%)$ & --- & --- & $2(14 \%)$ & --- & $5(36 \%)$ \\
\hline Comuna 9 & --- & $7(54 \%)$ & --- & --- & --- & $\begin{array}{l}1 \\
(8 \%)\end{array}$ & $5(38 \%)$ \\
\hline $\begin{array}{l}\text { Comuna } \\
14\end{array}$ & --- & $7(50 \%)$ & --- & --- & $1(7 \%)$ & $\begin{array}{l}2(14 \\
\%)\end{array}$ & $4(29 \%)$ \\
\hline $\begin{array}{l}\text { Otras } \\
\text { comunas }\end{array}$ & $1(5 \%)$ & $\begin{array}{l}12 \\
(57 \%)\end{array}$ & --- & --- & $1(5 \%)$ & --- & $7(33 \%)$ \\
\hline Total & $5(6 \%)$ & $\begin{array}{l}37 \\
(45 \%)\end{array}$ & $5(6 \%)$ & $1(1 \%)$ & $5(6 \%)$ & $\begin{array}{l}3 \\
(4 \%)\end{array}$ & $\begin{array}{l}27 \\
(33 \%)\end{array}$ \\
\hline
\end{tabular}

Fuente: Cálculos propios a partir de entrevistas a madres titulares

Ahorrar en la "alcancía" o "en efectivo" se constituye en el principal método de ahorro de las madres entrevistadas. Algunos mecanismos de ahorro se presentaron más frecuentemente en algunas comunas. Dentro de las madres lideres y titulares entrevistadas, varias de ellas (11) pertenecen al programa que tiene el Departamento de la Prosperidad social DPS, Ilamado Mujeres Ahorradoras, que consiste en que se capacitan un grupo de mujeres en emprendimiento y generación de ingresos y de igual forma se les capacita en un arte o manualidades y se les enseña a ahorra, de igual forma del valor ahorrado por cada madre el gobierno nacional les brinda un incentivo de mas , es decir por cada $\$ 100$ pesos ahorrados, el DPS, les da $\$ 50$. Es decir el $50 \%$ de lo que ahorre en un año, pero esos recursos deben ser destinados a la inversión, como compra de maquinaria, equipos de oficina, o cocina, en fin para desarrollar ejercicios laborales de acuerdo con la capacitación recibida, hay madres que han montado tiendas, salas de internet, compra de maquinaria para guarnición, costura. Entre otros. 
Otras maneras de ahorrar diferentes a las listadas en el Cuadro 8, pero que fueron mencionadas por las madres entrevistadas son ahorros a través de joyas ó prestando dinero.

Los ahorros son utilizados por las madres entrevistadas principalmente para enfrentar imprevistos o son destinados a la educación, alimentación y vestuario de los hijos. Las madres también ahorran para pagar deudas, incluyendo los servicios públicos, y para anticiparse a celebraciones o eventos especiales (Cuadro)

\section{Cuadro 9. Uso de los ahorros (número de madres) (porcentajes por comuna en paréntesis)}

\begin{tabular}{l|l|c|c|c|c|c|}
\hline Comuna & $\begin{array}{c}\text { Educación, } \\
\text { alimentación, } \\
\text { vestuario } \\
\text { para los hijos }\end{array}$ & $\begin{array}{c}\text { Eventos o } \\
\text { celebraciones } \\
\text { especiales }\end{array}$ & Imprevistos & $\begin{array}{c}\text { Pago de } \\
\text { servicios } \\
\text { y otras } \\
\text { deudas }\end{array}$ & $\begin{array}{c}\text { Invertir } \\
\text { en un } \\
\text { negocio }\end{array}$ & Otros \\
\hline Comuna 1 & --- & --- & $2(100 \%)$ & --- & --- & --- \\
\hline Comuna 2 & $2(20 \%)$ & $1(10 \%)$ & $2(20 \%)$ & $1(10 \%)$ & $2(20 \%)$ & $2(20 \%)$ \\
\hline Comuna 4 & $3(27 \%)$ & $2(18 \%)$ & $5(45 \%)$ & $1(9 \%)$ & --- & --- \\
\hline Comuna 9 & $4(25 \%)$ & $1(6 \%)$ & $4(25 \%)$ & $5(31 \%)$ & $1(6 \%)$ & $1(6 \%)$ \\
\hline $\begin{array}{l}\text { Comuna } \\
12\end{array}$ & $1(9 \%)$ & --- & $8(73 \%)$ & $1(9 \%)$ & $1(9 \%)$ & \\
\hline $\begin{array}{l}\text { Otras } \\
\text { comunas }\end{array}$ & $6(35 \%)$ & $2(12 \%)$ & $2(12 \%)$ & $2(12 \%)$ & --- & $5(29 \%)$ \\
\hline Total & $\mathbf{1 6 ( 2 4 \% )}$ & $\mathbf{6 ( 9 \% )}$ & $\mathbf{2 3 ( 3 4 \% )}$ & $\mathbf{1 0 ( 1 5 \% )}$ & $\mathbf{4 ( 6 \% )}$ & $\mathbf{8 ( 1 2 \% )}$ \\
\hline
\end{tabular}

Las cadenas o tandas consisten en un ahorro voluntario que hacen los ahorradores en períodos semanales, quincenales o mensuales con grupos de amigos, vecinos o familiares. Con la misma periodicidad de ahorro (semanal, quincenal, mensual) que es determinada entre los miembros del grupo de acuerdo a sus posibilidades, todos los ahorros recogidos de los miembros del grupo son entregados a uno de los ahorradores. 
Cuadro 10. ¿Hace cuánto tiempo ahorra?

\begin{tabular}{|l|c|c|c|c|}
\hline \multicolumn{1}{|c|}{ Comuna } & $\begin{array}{c}\text { Hace cuánto } \\
\text { tiempo } \\
\text { ahorras } \\
\text { (Meses) }\end{array}$ & $\begin{array}{c}\text { Mínimo } \\
\text { (Meses) }\end{array}$ & $\begin{array}{c}\text { Máximo } \\
\text { (Meses) }\end{array}$ & $\begin{array}{c}\text { Observaciones } \\
\text { (respuesta total) }\end{array}$ \\
\hline Comuna 1 & 24,0 & 12 & 36 & $2 / 6$ \\
\hline Comuna 2 & 56,0 & 9 & 240 & $5 / 9$ \\
\hline Comuna 4 & 47,1 & 2 & 144 & $9 / 14$ \\
\hline Comuna 9 & 21,3 & 1 & 84 & $8 / 13$ \\
\hline Comuna 14 & 67,5 & 12 & 168 & $11 / 20$ \\
\hline Otras comunas & 87,3 & 12 & 240 & $\mathbf{4 3 / 7 3}$ \\
\hline Total & $\mathbf{5 6 , 3}$ & $\mathbf{1}$ & $\mathbf{2 4 0}$ & \\
\hline
\end{tabular}

Fuente: Cálculos propios a partir de entrevistas a madres titulares

En la sección financiera de la entrevista se indagó a las madres respecto a las razones por la cuáles no ahorraban en alguna institución financiera. Se encontró que las madres no ahorran de manera formal, principalmente, porque consideran que no tienen suficiente dinero para ahorrar en entidades Financieras (Cuadro 11) o debido a los costos asociados al uso de este servicio financiero en entidades formales (cargos de manejo, cobros por transacción, etc.). El argumento de los costos de transacción, al igual que otras razones mencionadas por las madres entrevistadas, tales como desconfianza hacia las entidades financieras y la exigencia de excesivos requisitos en la documentación solicitada para abrir una cuenta de ahorros (trámites y papeleos), son reportadas por FELABAN (2007) como uno de los obstáculos importantes para la bancarización de la población de bajos ingresos en Latinoamérica. Estos obstáculos han sido también identificados en países como Brasil (Kumar, 2005) y reportados para Colombia (Dussán, 2008; Marulanda y Paredes, 2006; Documento CONPES, 3424). 
Cuadro 11. Razones por las cuáles las beneficiarias no ahorran en entidades financieras (Porcentajes por comuna en paréntesis)

\begin{tabular}{|l|c|c|c|c|c|c|}
\hline \multirow{2}{*}{ Comuna } & \multicolumn{6}{|c|}{ ¿Por qué no ahorra en entidades financieras? (número de madres) } \\
\cline { 2 - 7 } & $\begin{array}{c}\text { No confía } \\
\text { en las } \\
\text { entidades } \\
\text { financieras }\end{array}$ & $\begin{array}{c}\text { No sabe } \\
\text { cómo } \\
\text { hacerlo }\end{array}$ & $\begin{array}{c}\text { No tiene } \\
\text { suficiente } \\
\text { dinero }\end{array}$ & $\begin{array}{c}\text { Muchos } \\
\text { trámites y } \\
\text { papeleos }\end{array}$ & $\begin{array}{c}\text { Altos costos } \\
\text { asociados al } \\
\text { uso (costos } \\
\text { de } \\
\text { transacción) }\end{array}$ & Otros \\
\hline Comuna 1 & $1(33 \%)$ & --- & $1(33 \%)$ & $1(33 \%)$ & --- & --- \\
\hline Comuna 2 & --- & --- & $2(33 \%)$ & $3(50 \%)$ & --- & $1(17 \%)$ \\
\hline Comuna 4 & $1(11 \%)$ & --- & $3(33 \%)$ & $1(11 \%)$ & $4(44 \%)$ & --- \\
\hline Comuna 9 & $1(10 \%)$ & $1(10 \%)$ & $2(20 \%)$ & --- & $3(30 \%)$ & $3(30 \%)$ \\
\hline Comuna 14 & $1(14 \%)$ & & $3(43 \%)$ & --- & $1(14 \%)$ & $2(29 \%)$ \\
\hline $\begin{array}{l}\text { Otras } \\
\text { comunas }\end{array}$ & & $3(25 \%)$ & $5(42 \%)$ & --- & $3(25 \%)$ & $1(8 \%)$ \\
\hline Total & $\mathbf{4 ( 9 \% )}$ & $\mathbf{4 ( 9 \% )}$ & $\mathbf{1 6 ( 3 4 \% )}$ & $\mathbf{5 ( 1 1 \% )}$ & $\mathbf{1 1 ( 2 3 \% )}$ & $\mathbf{7 ( 1 5 \% )}$ \\
\hline
\end{tabular}

Fuente: Cálculos propios a partir de entrevistas a madres titulares

Otros motivos por los cuáles las madres entrevistadas no ahorran en una entidad formal podrían estar asociados a razones culturales o de falta de conocimiento financiero como "no me gusta", "no tengo la costumbre", "nunca lo había pensado", o "por descuido propio", razones asociadas a Autoexclusión del sector financiero (Maldonado, 2004)

El ahorro mensual de las madres entrevistadas presenta variaciones amplias cuyos promedios Oscilan entre $\$ 10.000$ y $\$ 250.000$ (Cuadro 12). Vale la pena resaltar que aunque el promedio de ahorro mensual del hogar para todas las comunas es de algo menos de $\$ 60.000$ ( $\$ 2.000$ diarios), se reportan algunos valores cercanos a los $\$ 200.000$ pesos, que se puede considerar una cifra de ahorro alta si se compara con el ingreso promedio reportado por hogar (aproximadamente \$426.000). Sin embargo, eliminado los cuatro casos donde las madres reportan valores elevados de ahorro mensual ( $\$ 175.000, \$ 180.000$ y dos de $\$ 250.000)$, el promedio de ahorro para las otras madres entrevistadas. Se reduce aproximadamente a $\$ 45.000$ ( $\$ 1.500$ diarios).se reduce aproximadamente a $\$ 45.000$ ( $\$ 1.500$ diarios). 
Cuadro 12. Promedio de ahorros mensuales del hogar

\begin{tabular}{|l|l|l|l|l|}
\hline Comuna & $\begin{array}{c}\text { Ahorros } \\
\text { promedio por } \\
\text { mes }\end{array}$ & \multicolumn{1}{|c|}{$\begin{array}{c}\text { Máximo } \\
\text { ( COP\$) }\end{array}$} & $\begin{array}{c}\text { Mínimo } \\
\text { (COP\$) }\end{array}$ & $\begin{array}{c}\text { OBSERVACIONES } \\
\text { (respuesta total) }\end{array}$ \\
\hline Comuna 1 & $\$ 30.000$ & $\$ 30.000$ & $\$ 30.000$ & $1 / 6$ \\
\hline Comuna 2 & $\$ 63.314$ & $\$ 180.000$ & $\$ 20.000$ & $7 / 9$ \\
\hline Comuna 4 & $\$ 37.111$ & $\$ 70.000$ & $\$ 10.000$ & $9 / 14$ \\
\hline Comuna 9 & $\$ 59.500$ & $\$ 100.00$ & $\$ 10.000$ & $10 / 13$ \\
\hline Comuna 14 & $\$ 50.714$ & $\$ 125.000$ & $\$ 15.000$ & $7 / 11$ \\
\hline Otras comunas & $\$ 77.500$ & $\$ 250.000$ & $\$ 10.000$ & $14 / 20$ \\
\hline Total & $\$ 58.156$ & $\$ 250.000$ & $\$ 10.000$ & $48 / 73$ \\
\hline
\end{tabular}

Fuente: Cálculos propios a partir de entrevistas a madres titulares

\section{Crédito}

Las madres entrevistadas manifestaron acceder a diferentes tipos de créditos o préstamos entre los que se encuentran créditos formales y préstamos informales bajo las modalidades gota a gota o paga diario y empeño. Adicionalmente, las madres reportaron recibir con frecuencia préstamos de amigos o familiares, estos últimos caracterizados por ser de pequeños montos y por intereses más bajos que los asociados a otras formas de crédito informal o, incluso, sin pago de intereses.

La informalidad caracteriza los créditos o préstamos de las madres entrevistadas. La modalidad de préstamos del tipo "gota a gota" -conocida también como paga diario-consiste, en términos generales, en que por cada 100 mil pesos de préstamo, el deudor debe pagar cuotas diarias de aproximadamente $\$ 4.000$ pesos diarios durante 30 días o $\$ 2.000$ pesos durante dos meses, alcanzado tasas de intereses hasta del $20 \%$ mensual.

El prestamista tiene cobradores que van de casa en casa cobrando la cuota diaria. Estos arreglos de pagos pueden ser también semanales o quincenales y en la mayoría de los casos son considerados como una actividad de usura. En general, los clientes de esta modalidad de préstamo son personas de bajos ingresos, quienes no tienen acceso real a los créditos del sistema financiero formal. Los prestamistas de la modalidad gota a gota diversifican el riesgo al enfocar su negocio en préstamos pequeños a un mayor número de 
personas en lugar de hacer grandes préstamos a unas pocas.34 madres de las 73 entrevistadas afirmaron tener actualmente préstamos bajo la modalidad gota agota.

Cuadro 13. Madres entrevistadas con préstamos del tipo gota a gota 0 paga diario (entre paréntesis porcentaje con respecto al total de entrevistas)

\begin{tabular}{|c|c|}
\hline Comuna & $\begin{array}{l}\text { Numero de entrevistas que tiene o ha tenido préstamos en la modalidad } \\
\text { gota a gota. }\end{array}$ \\
\hline Comuna 1 & $1(17 \%)$ \\
\hline Comuna 2 & $4(44 \%)$ \\
\hline Comuna 4 & $3(21 \%)$ \\
\hline Comuna 9 & $9(69 \%)$ \\
\hline Comuna 14 & $6(55 \%)$ \\
\hline Otras comunas & $11(55 \%)$ \\
\hline Total & 34 (47\%) \\
\hline
\end{tabular}

Fuente: Cálculos propios a partir de entrevistas a madres titulares

Las madres entrevistadas reportan utilizar la modalidad de crédito gota a gota principalmente para el pago de servicios públicos y para surtir los negocios, generalmente informales, del hogar. Este tipo de préstamo es usado en menor proporción por las madres entrevistadas para enfrentar imprevistos, como enfermedades o pérdida del empleo, para suplir necesidades de educación, vestuario y alimentación y para pagar el arriendo (Cuadro 14) 


\section{Cuadro 14. Uso de los créditos gota a gota o paga diario (porcentajes por comuna en paréntesis)}

\begin{tabular}{|c|c|c|c|c|c|c|}
\hline \multirow{2}{*}{ Comunas } & \multicolumn{6}{|c|}{ ¿Para qué ha solicitado créditos gota a gota o paga diario? } \\
\hline & $\begin{array}{l}\text { Educación, } \\
\text { vestuario, } \\
\text { alimentación }\end{array}$ & $\begin{array}{l}\text { Pago de } \\
\text { servicios } \\
\text { públicos }\end{array}$ & $\begin{array}{l}\text { Surtir el } \\
\text { negocio }\end{array}$ & $\begin{array}{l}\text { Pago de } \\
\text { arriendo }\end{array}$ & $\begin{array}{c}\text { Imprevistos } \\
\text { (enfermedad) }\end{array}$ & Otros \\
\hline $\begin{array}{c}\text { Comuna } \\
1\end{array}$ & --- & $1(100 \%)$ & --- & --- & --- & --- \\
\hline $\begin{array}{c}\text { Comuna } \\
2\end{array}$ & --- & $2(50 \%)$ & --- & --- & --- & $\begin{array}{c}2 \\
(50 \%)\end{array}$ \\
\hline $\begin{array}{c}\text { Comuna } \\
4\end{array}$ & $1(33 \%)$ & $1(33 \%)$ & --- & --- & $1(33 \%)$ & --- \\
\hline $\begin{array}{c}\text { Comuna } \\
9\end{array}$ & $1(11 \%)$ & --- & $4(44 \%)$ & --- & $1(11 \%)$ & $\begin{array}{c}3 \\
(33 \%)\end{array}$ \\
\hline $\begin{array}{c}\text { Comuna } \\
14\end{array}$ & $1(14 \%)$ & $3(43 \%)$ & $1(14 \%)$ & $1(14 \%)$ & $1(14 \%)$ & --- \\
\hline $\begin{array}{c}\text { Otras } \\
\text { comunas }\end{array}$ & $3(21 \%)$ & $3(21 \%)$ & $2(14 \%)$ & $3(21 \%)$ & 2 (14\%) & $\begin{array}{c}1 \\
(7 \%)\end{array}$ \\
\hline Total & $6(16 \%)$ & $10(26 \%)$ & $7(18 \%)$ & $4(11 \%)$ & $5(13 \%)$ & $\begin{array}{c}6 \\
(16 \%)\end{array}$ \\
\hline
\end{tabular}

Fuente: Cálculos propios a partir de entrevistas a madres titulares

Las madres entrevistadas en las seis comunas del Municipio de Bucaramanga de este estudio, solicitan bajo la modalidad gota agota, en promedio, \$165.000 (Cuadro 15), en un rango que varía entre \$50.000 y $\$ 400.000$. En esta modalidad, las cuotas son pagadas semanalmente o a diario; de ahí su nombre "gota a gota o paga diario". El monto diario pagado, que depende de la cantidad prestada y el plazo para el pago, oscila entre $\$ 2.000$ y $\$ 12.000$, con un promedio de aproximadamente $\$ 4.800$ (Cuadro 15). Por otro lado, los plazos para pago también varían dependiendo del monto y no superan los 4 meses, siendo el plazo mínimo 30 días y el promedio un mes y medio (Cuadro 15). 
Cuadro 15. Características de los préstamos en la modalidad gota a gota

\begin{tabular}{|l|l|l|l|l|}
\hline Comuna & $\begin{array}{c}\text { Monto } \\
\text { promedio } \\
\text { solicitado } \\
\mathbf{( \$ )}\end{array}$ & $\begin{array}{c}\text { Plazo promedio } \\
\text { para pago } \\
\text { (Días) }\end{array}$ & $\begin{array}{c}\text { Pago diario } \\
\text { promedio } \\
\mathbf{( \$ )}\end{array}$ & $\begin{array}{c}\text { Interés } \\
\text { promedio } \\
\text { mensual } \\
\mathbf{( \$ )}\end{array}$ \\
\hline Comuna 1 & 280.000 & 90 & 6.000 & 6.25 \\
\hline Comuna 2 & 100.000 & 30 & 4.000 & 20.00 \\
\hline Comuna 4 & 135.714 & 31 & 4.857 & 19.30 \\
\hline Comuna 9 & 150.000 & 42 & 3.800 & 15.00 \\
\hline Comuna 14 & 177.778 & 48 & 5.222 & 13.90 \\
\hline Total & 165.000 & $\mathbf{4 5}$ & $\mathbf{4 . 7 8 3}$ & 15.31 \\
\hline
\end{tabular}

Fuente: Cálculos propios a partir de entrevistas a madres titulares

Las tasas de interés mensual que cobran los prestamistas en la modalidad gota a gota es, en promedio para cinco comunas, de 15,3\% (Cuadro 15).

Las madres entrevistadas también reportaron el uso de préstamos bajo empeño. Esta modalidad consiste en solicitar préstamos dejando como prenda de garantía un bien de valor del hogar, siendo los más usuales las joyas y los electrodomésticos.

De las 73 madres entrevistadas, 36 afirmaron haber empeñado algún bien (Cuadro 16).

Cuadro 16. Madres entrevistadas con préstamos bajo la modalidad de empeño (entre paréntesis porcentaje con respecto al total de entrevistas)

\begin{tabular}{|l|c|}
\hline Comuna & $\begin{array}{c}\text { Número de madres entrevistadas que tiene o ha tenido préstamos } \\
\text { en la modalidad de empeño }\end{array}$ \\
\hline Comuna 1 & $3(50 \%)$ \\
\hline Comuna 2 & $3(33 \%)$ \\
\hline Comuna 4 & $8(57 \%)$ \\
\hline Comuna 9 & $8(62 \%)$ \\
\hline Comuna 14 & $5(45 \%)$ \\
\hline Otras comunas & $7(35 \%)$ \\
\hline Total & $36(49 \%)$ \\
\hline
\end{tabular}

Fuente: Cálculos propios a partir de entrevistas a madres titulares 
Es común que las madres empeñen joyas y electrodomésticos, principalmente televisores (Cuadro17). Más de la mitad de las madres que reportaron haber recurrido al empeño (19 madres), afirmaron haber perdido los bienes entregados como garantía del préstamo.

Cuadro 17. Frecuencia de bienes empeñados por las madres entrevistadas

\begin{tabular}{|l|c|}
\hline \multicolumn{1}{|c|}{ BIEN } & NUMERO DE VECES \\
\hline JOYAS & 18 \\
\hline TELEVISOR & 7 \\
\hline OTROS & 15 \\
\hline
\end{tabular}

Fuente: Cálculos propios a partir de entrevistas a madres titulares

Otros artículos que se empeñan en los hogares de las madres beneficiarias son grabadoras, DVD, ollas, máquinas de coser y licuadoras, celulares bicicletas y motos

El empeño de los bienes del hogar o joyas se constituye en una estrategia utilizada por algunas madres, principalmente para hacer frente a imprevistos o calamidades domésticas, para la compra de alimentos para el hogar y para pagar otras deudas (Cuadro 18). El empeño es un mecanismo que parece ser muy útil a la hora de enfrentar shocks, particularmente aquellos relacionados con enfermedades o accidentes de algún miembro del hogar.

\section{Cuadro 18. Usos de los préstamos bajo modalidad de empeño (porcentajes por Comuna en Paréntesis)}

\begin{tabular}{|l|l|l|l|l|l|l|}
\hline \multirow{2}{*}{ Comunas } & \multicolumn{6}{|c|}{ ¿Para qué ha solicitado préstamos bajo la modalidad de empeño? } \\
\cline { 2 - 8 } & $\begin{array}{c}\text { Imprevistos } \\
\text { (numero de madres) } \\
\text { calamidad } \\
\text { doméstica }\end{array}$ & $\begin{array}{c}\text { Pago del } \\
\text { arriendo }\end{array}$ & $\begin{array}{c}\text { Compra } \\
\text { de } \\
\text { alimentos }\end{array}$ & $\begin{array}{c}\text { Pago de } \\
\text { deudas }\end{array}$ & $\begin{array}{c}\text { Gastos de } \\
\text { educación } \\
\text { de } \\
\text { Los hijos. }\end{array}$ & Otros \\
\hline Comuna 1 & $1(33 \%)$ & $1(33 \%)$ & --- & --- & --- & $1(33 \%)$ \\
\hline Comuna 2 & $3(100 \%)$ & ------ & -- & - & \\
\hline Comuna 4 & $2(20 \%)$ & $1(10 \%)$ & $4(40 \%)$ & $3(30 \%)$ & -- & $1(11 \%)$ \\
\hline Comuna 9 & $3(33 \%)$ & $1(11 \%)$ & $2(22 \%)$ & --- & $2(22 \%)$ & $1(20 \%)$ \\
\hline Comuna 14 & $2(40 \%)$ & $1(20 \%)$ & $1(20 \%)$ & --- & $14 \%)$ \\
\hline $\begin{array}{l}\text { Otras } \\
\text { comunas }\end{array}$ & $2(29 \%)$ & ---- & $1(14 \%)$ & $3(43 \%)$ & -- & $1(14 \%)$ \\
\hline Total & $\mathbf{1 3 ( 3 5 \% )}$ & $\mathbf{4 ( 1 1 \% )}$ & $\mathbf{8 ( 2 2 \% )}$ & $\mathbf{6 ( 1 6 \% )}$ & $\mathbf{3 ( 8 \% )}$ & $\mathbf{3 ( 8 \% )}$ \\
\hline
\end{tabular}

Fuente: Cálculos propios a partir de entrevistas a madres titulares 
Nótese que, de manera similar al ahorro, los préstamos bajo la modalidad de empeño parecen ser utilizados más frecuentemente para enfrentar imprevistos o calamidades domésticas; sin embargo, esta estrategia conduce muchas veces a la pérdida de los bienes del hogar. A este respecto, Morduch (1999) arguye que precisamente la falta de herramientas de ahorro apropiadas impide que los hogares aseguren el consumo en presencia de shocks. Los montos de los préstamos adquiridos bajo la modalidad de empeño están, como es de esperarse, directamente relacionados con el bien empeñado. Las madres entrevistadas reportan bajo esta modalidad préstamos promedio de aproximadamente $\$ 100.000$ (Cuadro 19), con mínimos de $\$ 20.000$ y máximos de $\$ 400.000$. Los intereses mensuales pagados son, en promedio, más bajos que los intereses reportados bajo la modalidad gota a gota en algo más de 5 puntos porcentuales(Cuadros $15 \mathrm{y}$ 19 ), alcanzando en promedio cerca del $10 \%$ mensual. Con respecto a los plazos pactados para el pago de los préstamos bajo empeño, el promedio reportado por las madres entrevistadas es de 4 meses (Cuadro 19), muy superior al promedio del plazo en la modalidad gota a gota, aunque varía, entre un mínimo de un mes y un máximo de 6 meses.

\section{Cuadro 19. Características de los préstamos bajo la modalidad de empeño}

\begin{tabular}{|l|c|c|c|}
\hline Comuna & $\begin{array}{c}\text { Monto promedio } \\
\text { otorgado (\$) }\end{array}$ & $\begin{array}{c}\text { Plazo promedio } \\
\text { para pago } \\
\text { (días) }\end{array}$ & $\begin{array}{c}\text { Interés promedio } \\
\text { Mensual }\end{array}$ \\
\hline Comuna 1 & 30.000 & 120 & 6.60 \\
\hline Comuna 2 & 150.000 & 180 & 10.00 \\
\hline Comuna 4 & 223.333 & 108 & 5.60 \\
\hline Comuna 9 & 122.500 & 180 & 11.11 \\
\hline Comuna 14 & 70.000 & 70 & 12.63 \\
\hline Otras comunas & 53.333 & 85 & $\mathbf{9 . 4 4}$ \\
\hline Total & $\mathbf{1 0 3 . 8 8 8}$ & $\mathbf{1 2 0}$ & \\
\hline
\end{tabular}

Fuente: Cálculos propios a partir de entrevistas a madres titulares

Es interesante notar que varias madres entrevistadas reportaron el uso de créditos formales, otorgados por entidades financieras o micro financieras y cooperativas de ahorro, entre otros. De las73 madres entrevistadas en las seis ciudades, 23 reportaron haber solicitado y recibido crédito de una entidad financiera (Cuadro 20). 
Cuadro 20. Madres entrevistadas con créditos formales (entre paréntesis porcentaje con

Respecto al total de entrevistas)

\begin{tabular}{|l|c|}
\hline Comuna & $\begin{array}{c}\text { Número de madres entrevistadas que tiene o ha tenido } \\
\text { créditos de entidades financieras }\end{array}$ \\
\hline Comuna 1 & $1(17 \%)$ \\
\hline Comuna 2 & $4(44 \%)$ \\
\hline Comuna 4 & $5(36 \%)$ \\
\hline Comuna 9 & $6(46 \%)$ \\
\hline Comuna 14 & $3(27 \%)$ \\
\hline Otras comunas & $4(20 \%)$ \\
\hline Total & $\mathbf{2 3 ( 3 2 \% )}$ \\
\hline
\end{tabular}

Como se observa en el Cuadro 21, la mayoría de las madres entrevistadas han destinado los créditos otorgados por entidades formales para establecer o mejorar un negocio propio o para realizar mejoras de la vivienda, o arreglos locativos de la vivienda. Es decir, este crédito es principalmente productivo o para inversión, bien sea en el negocio o en el hogar.

Cuadro 21. Uso del crédito formal (porcentajes por comuna en paréntesis)

\begin{tabular}{|l|c|c|c|c|}
\hline \multirow{2}{*}{ comuna } & \multicolumn{4}{|c|}{ ¿Para qué ha solicitado créditos formales? (número de madres) } \\
\cline { 2 - 5 } & $\begin{array}{c}\text { Establecer o } \\
\text { mejorar } \\
\text { un negocio }\end{array}$ & $\begin{array}{c}\text { Compra o } \\
\text { arreglo } \\
\text { de vivienda }\end{array}$ & $\begin{array}{c}\text { Compra de } \\
\text { electrodomésticos }\end{array}$ & Otro \\
\hline Comuna 1 & $1(100 \%)$ & --- & --- & -- \\
\hline Comuna 2 & $1(20 \%)$ & $2(40 \%)$ & $1(20 \%)$ & $1(20 \%)$ \\
\hline Comuna 4 & $3(50 \%)$ & $2(33 \%)$ & $1(17 \%)$ & --- \\
\hline Comuna 9 & $4(57 \%)$ & $1(14 \%)$ & --- & --- \\
\hline Comuna 12 & $3(75 \%)$ & --- & $1(25 \%)$ & -- \\
\hline $\begin{array}{l}\text { Otras } \\
\text { comunas }\end{array}$ & $3(75 \%)$ & $1(25 \%)$ & --- & $3(11 \%)$ \\
\hline Total & $\mathbf{1 5 ( 5 6 \% )}$ & $\mathbf{6 ( 2 2 \% )}$ & $\mathbf{3 ( 1 1 \% )}$ & \\
\hline
\end{tabular}


Los créditos formales han sido otorgados por entidades como cooperativas de ahorros, bancos

Entidades comerciales -incluido el Banco Agrario-, empresas privadas de venta de electrodomésticos entidades dedicadas exclusivamente a ofrecer servicios de micro finanzas (Fundación Mundo Mujer) (Cuadro 22).

\section{Cuadro 22. Entidad que otorgó el crédito formal}

\begin{tabular}{|c|c|}
\hline comuna & Entidades reportadas \\
\hline Comuna 1 & Cooperativa de Ahorros \\
\hline Comuna 2 & $\begin{array}{c}\text { Colpatria (1 (1), Banco de la Mujer (1), uno cuyo nombre no fue } \\
\text { reportado }\end{array}$ \\
\hline Comuna 4 & Banco Caja Social (2), Fundación Mundo Mujer (2), Banco Agrario (1) \\
\hline Comuna 9 & $\begin{array}{l}\text { Fundación Mundo Mujer (4), Fundación Producir de Visión Mundial (1), } \\
\text { uno cuyo } \\
\text { nombre no fue reportado }\end{array}$ \\
\hline Comuna 14 & Banco Agrario (1), Fundación Mundo Mujer (2) \\
\hline Otras comunas & Fundación Mundo Mujer (2), Coomultrasan (1), \\
\hline Total & 23 \\
\hline
\end{tabular}

Fuente: Cálculos propios a partir de entrevistas a madres titulare

Algunas de las entidades mencionadas, como la Fundación Mundo Mujer y el Banco de la Mujer, tienen, como se deduce de su nombre, focalización hacia las mujeres y cuentan con cobertura a lo largo de la geografía nacional. Particularmente, los créditos de la Fundación Mundo Mujer parecen ser muy importantes entre las madres beneficiarias del programa Familias en Acción: diez de las mujeres entrevistadas que reportaron tener un crédito formal (23 madres), son clientes de esta entidad. La Fundación Mundo Mujer, creada en el año 1985, es una fundación sin ánimo de lucro que tiene como propósito principal mejorar la calidad de vida de la mujer trabajadora de escasos recursos y de su familia, mediante el acceso fácil y oportuno al crédito y otros servicios; esta entidad tiene presencia en todo el país (36 sedes)

Aunque 23 madres entrevistadas reportaron tener crédito formal, solamente cinco ofrecieron información precisa sobre el mismo, contrario a lo reportado para las modalidades informales de crédito. Estas cinco madres reportaron créditos que oscilan entre $\$ 300.000$ y $\$ 1.000 .000$ y pagan intereses que no superan el $5 \%$ mensual (Cuadro 23), como de esperarse mucho menores a los intereses pagados bajo las modalidades de gota a gota y empeño. 


\section{Cuadro 23. Características de los créditos formales}

\begin{tabular}{|l|l|l|l|l|}
\hline Comuna & \multicolumn{1}{|c|}{$\begin{array}{c}\text { Monto } \\
\text { otorgado } \\
\mathbf{( \$ )}\end{array}$} & $\begin{array}{c}\text { Plazo para } \\
\text { pago } \\
\text { (meses) }\end{array}$ & $\begin{array}{c}\text { Monto } \\
\text { promedio de la } \\
\text { cuota (\$) }\end{array}$ & $\begin{array}{c}\text { Interés } \\
\text { promedio } \\
\text { mensual (\%) }\end{array}$ \\
\hline Comuna 1 & 300.000 & 4 & 80.000 & 1.67 \\
\hline Comuna 2 & 300.000 & 5 & 64.000 & 1.33 \\
\hline Comuna 4 & 400.000 & 6 & 75.000 & 2.08 \\
\hline Comuna 9 & 1.000 .000 & 24 & 60.000 & 1.83 \\
\hline Total & $\mathbf{1 . 0 0 0 . 0 0 0}$ & $\mathbf{1 2}$ & $\mathbf{1 2 5 . 0 0 0}$ & $\mathbf{4 . 1 7}$ \\
\hline
\end{tabular}

Fuente: Cálculos propios a partir de entrevistas a madres titulares

Como se puede observar, las diferentes fuentes de crédito usadas por las madres entrevistadas tienen nichos y usos diferentes: los créditos informales (oportunos pero costosos) se usan más para atender emergencias 0 necesidades urgentes, es decir como mecanismos de suavización del consumo, mientras que los créditos formales (menos costosos pero asociados a muchos requisitos) se destinan más a la inversión en negocios o en el hogar, es decir como mecanismos de suavización del ingreso.

\section{Shocks y estrategias}

Las madres titulares entrevistadas reportan una variedad de estrategias para enfrentar shocks o acontecimientos idiosincráticos o situaciones imprevistas (muerte o enfermedad de algún miembro de la familia, desempleo, etc.). La principal estrategia utilizada por las madres beneficiarias es pedir prestado a familiares o amigos (35 madres). Otras estrategias frecuentes son utilizar los ahorros (15madres), hacer colectas (15) y empeñar (13 madres). 
Cuadro 24. Estrategias de las madres para enfrentar shocks 0 acontecimientos (porcentajes por comuna en paréntesis)

\begin{tabular}{|c|c|c|c|c|c|c|c|}
\hline \multirow{2}{*}{ Comuna } & \multicolumn{7}{|c|}{ Estrategias para enfrentar shocks (número de madres) } \\
\hline & $\begin{array}{l}\text { Pedir } \\
\text { prestado } \\
\text { a } \\
\text { amigo o } \\
\text { familiar }\end{array}$ & $\begin{array}{l}\text { Pedir } \\
\text { prestado } \\
\text { gota a } \\
\text { gota }\end{array}$ & Empeñar & $\begin{array}{l}\text { Gastar } \\
\text { ahorros }\end{array}$ & $\begin{array}{l}\text { Trabajar } \\
\text { extra }\end{array}$ & $\begin{array}{l}\text { Hizo una } \\
\text { recolecta }\end{array}$ & Otro \\
\hline Comuna 1 & $4(57 \%)$ & --- & --- & $2(29 \%)$ & --- & --- & $\begin{array}{c}1 \\
(14 \%)\end{array}$ \\
\hline Comuna 2 & $5(56 \%)$ & --- & --- & $2(22 \%)$ & --- & $2(22 \%)$ & \\
\hline Comuna 4 & $6(30 \%)$ & $1(5 \%)$ & $3(15 \%)$ & $3(15 \%)$ & --- & $4(20 \%)$ & $\begin{array}{c}3 \\
(15 \%)\end{array}$ \\
\hline Comuna 9 & $6(29 \%)$ & $2(10 \%)$ & $5(24 \%)$ & $4(19 \%)$ & $2(10 \%)$ & $2(10 \%)$ & --- \\
\hline Comuna & $5(36 \%)$ & $2(14 \%)$ & $3(21 \%)$ & $2(14 \%)$ & --- & $2(14 \%)$ & --- \\
\hline $\begin{array}{l}\text { Otras } \\
\text { comunas }\end{array}$ & 9 (38\%) & $1(4 \%)$ & $2(8 \%)$ & $3(13 \%)$ & $1(4 \%)$ & $5(21 \%)$ & $\begin{array}{c}3 \\
(13 \%)\end{array}$ \\
\hline Total & 35 (37\%) & $6(6 \%)$ & $13(14 \%)$ & $1617 \%)$ & $3(3 \%)$ & $15(16 \%)$ & $7(7 \%)$ \\
\hline
\end{tabular}

Fuente: Cálculos propios a partir de entrevistas a madres titulares

La Bancarización de las madres beneficiarias del programa FA como estrategia de suavización del consumo y el ingreso

Las transferencias condicionadas otorgadas por el Programa Familias en Acción han sido entregadas a las madres beneficiarias utilizando tres mecanismos de pago: i) pago directo "en efectivo", ii) monedero electrónico o tarjeta electrónica recargable (conocida por las madres como "la tarjeta del Banco Popular") y iii) cuenta de ahorros electrónica o bancarización (conocida entre las madres como "la tarjeta del Banco Agrario").Inicialmente -y por varios años-, los subsidios se entregaron efectuando el "pago directo en efectivo"; este mecanismo, a su vez, podía realizarse bajo tres modalidades de acuerdo a la localización de beneficiario y a la presencia o no de una entidad financiera en el municipio: i) pago en municipio beneficiario, ii) pago por caja extendida y iii) pago en municipio vecino. Sin embargo, y a pesar de su efectividad -principalmente en municipios rurales aislados- este sistema resultó en altas congestiones, debido a la baja capacidad física y operativa de las sucursales en los bancos asociados y al flujo incrementado de clientes durante los periodos de pago. 
Como alternativa para superar las dificultades presentadas con el mecanismo de pago directo en efectivo, se implementó un nuevo mecanismo de pago denominado "monedero electrónico". Bajo este mecanismo, el programa entregó a las madres beneficiarias una tarjeta electrónica debito de cuenta de ahorros, en donde FA depositaba el dinero del subsidio y los beneficiarios podían retirarlo a través de algunos cajeros electrónicos. Esta tarjeta, además de tener altos costos de operación para el programa, imposibilitaba a las madres retirar la totalidad de los subsidios y, al no estar ligada a una cuenta bancaria, no les permitía ahorrar. De hecho, el dinero que no se retiraba después de algún tiempo era retirado de la cuenta.

Con el objetivo principal de mejorar la eficiencia en la entrega de la transferencia y superar dificultades presentadas con otras modalidades de pago, desde el año 2009 el programa FA inició un ambicioso Plan de Bancarización de las familias beneficiarias. Como se mencionó anteriormente, la bancarización de las familias receptoras de los subsidios de FA tiene el objetivo complementario de fomentar el ahorro y favorecer el acceso a otros servicios financieros por parte de esta población vulnerable.

En esta sección, y con el objetivo de analizar la importancia de la bancarización como mecanismo de suavización del ingreso y del consumo de los hogares beneficiarios de este programa de transferencias condicionadas, se presentan los resultados de las percepciones que las madres Beneficiarias entrevistadas tienen respecto a las ventajas y desventajas de la bancarización, a menos de un año de iniciado el plan.

Principalmente, costos de manejo y reposición de tarjeta. Debido a que los cajeros únicamente permiten retiros en múltiplos de $\$ 10.000$ pesos. Montos menores no podían ser retirados, de manera que las madres -en algunos casos- no podían retirar la totalidad del subsidio.

El Cuadro 26 muestra el número de madres entrevistadas, clasificadas de acuerdo a los mecanismos

De pago a los que han estado vinculadas durante su estadía en el programa de FA. Por ejemplo, las madres tipo uno, son aquellas madres que solamente han recibido pagos en la modalidad efectivo ó

"carta-cheque"; mientras que las madres tipo $\mathrm{VI}$, son aquellas madres que han recibido el pago del subsidio bajos los tres mecanismos de pago: efectivo, monedero electrónico (tarjeta del Banco Agrario). 


\section{Cuadro 26. Número de madres entrevistadas de acuerdo al mecanismo de pago del subsidio}

\begin{tabular}{|c|c|c|}
\hline Tipo de madre & Mecanismo de pagos & Numero de madres \\
\hline Madre tipo I & $\begin{array}{l}\text { Solamente Efectivo o carta } \\
\text { cheque }\end{array}$ & $1(1 \%)$ \\
\hline Madre tipo II & $\begin{array}{c}\text { Solamente monedero } \\
\text { electrónico (Tarjeta Banco } \\
\text { Popular) }\end{array}$ & --- \\
\hline Madre tipo III & $\begin{array}{c}\text { Solamente Bancarización (Tarjeta } \\
\text { Banco Agrario) }\end{array}$ & $4(5 \%)$ \\
\hline Madre tipo IV & $\begin{array}{c}\text { Efectivo + monedero } \\
\text { electrónico (Tarjeta Banco } \\
\text { Popular) }\end{array}$ & --- \\
\hline Madre tipo V & $\begin{array}{c}\text { Efectivo + Bancarización } \\
\text { (Tarjeta Banco Agrario) } \\
\text { Monedero Electrónico (Tarjeta } \\
\text { Banco Popular) }\end{array}$ & $4(5 \%)$ \\
\hline Madre tipo VI & $\begin{array}{c}\text { Bancarización (Tarjeta Banco } \\
\text { Agrario)Efectivo + Monedero } \\
\text { electrónico (Tarjeta Banco } \\
\text { Popular) }\end{array}$ & $7(10 \%)$ \\
\hline Madre tipo VII & $\begin{array}{c}\text { Bancarización (Tarjeta Banco } \\
\text { Agrario) }\end{array}$ & $56(77 \%)$ \\
\hline
\end{tabular}

Fuente: Cálculos propios a partir de entrevistas a madres titulares

El Cuadro 26 muestra que la mayoría de las madres entrevistadas (67/72) estaban bancarizadas al momento de la entrevista. Comparando los tres mecanismos, las madres beneficiarias entrevistadas consideran, en su mayoría, que la principal ventaja de la bancarización (tarjeta del Banco Agrario) es que les permite ahorrar. Además del acceso al ahorro, a través de la bancarización, las madres mencionan con frecuencia ventajas similares a las mencionadas para el mecanismo de monedero electrónica, la mayoría de ellas relacionadas con aumento en la eficiencia en el proceso, asociada a su vez, a ahorros de tiempo (Cuadro 27)

Una de las madres entrevistadas en la ciudad de la comuna 2 manifestó pertenecer al programa hace tres meses pero no había recibido ningún pago en el momento de la entrevista. Conveniencia particular de tiempo y localización, ii) mayor facilidad y rapidez del proceso, iii) menos filas y iv) mayor cobertura de sitios de pago. Ventajas similares fueron reportadas por PATH (2007) y Duryea y Schargrodsky (2008) para procesos de 
bancarización en programas de trasferencias condicionadas en Jamaica y Argentina, respectivamente. Entre otras ventajas expuestas por las madres se encuentran la seguridad, la posibilidad de consultar el saldo a través dela línea gratuita, la organización, la modernización del proceso y la posibilidad de que alguien más haga el retiro del subsidio.

\section{Cuadro 27. Ventajas de la Bancarización (tarjeta del Banco Agrario)}

\begin{tabular}{|l|c|c|c|c|c|c|}
\hline \multirow{2}{*}{ Comuna } & \multicolumn{6}{|c|}{ Ventajas del pago con la Tarjeta del Banco Agrario (número de madres) } \\
\cline { 2 - 7 } & $\begin{array}{c}\text { Se } \\
\text { puede } \\
\text { ahorrar }\end{array}$ & $\begin{array}{c}\text { Mayor } \\
\text { facilidad/ } \\
\text { rapidez } \\
\text { para } \\
\text { cobrar }\end{array}$ & $\begin{array}{c}\text { No se } \\
\text { forman } \\
\text { filas }\end{array}$ & $\begin{array}{c}\text { Se retira en } \\
\text { dinero según } \\
\text { conveniencia } \\
\text { de tiempo y } \\
\text { lugar }\end{array}$ & $\begin{array}{c}\text { Mayor cobertura } \\
\text { de sitios de pago } \\
\text { (cajeros y } \\
\text { supermercados) }\end{array}$ & Otro \\
\hline Comuna 1 & $3(38 \%)$ & $2(25 \%)$ & $1(13 \%)$ & $1(13 \%)$ & --- & $1(13 \%)$ \\
\hline Comuna 2 & $2(22 \%)$ & --- & $1(11 \%)$ & $4(44 \%)$ & --- & $2(22 \%)$ \\
\hline Comuna 4 & $1(7 \%)$ & $4(29 \%)$ & $1(7 \%)$ & $3(21 \%)$ & $2(14 \%)$ & $3(21 \%)$ \\
\hline Comuna 9 & $7(50 \%)$ & --- & $2(14 \%)$ & $2(14 \%)$ & $2(14 \%)$ & $1(7 \%)$ \\
\hline Comuna 14 & $4(27 \%)$ & $1(7 \%)$ & $1(7 \%)$ & $4(27 \%)$ & $2(13 \%)$ & $3(20 \%)$ \\
\hline $\begin{array}{l}\text { Otras } \\
\text { comunas }\end{array}$ & $3(12 \%)$ & $3(12 \%)$ & $6(23 \%)$ & $5(19 \%)$ & $4(15 \%)$ & $5(19 \%)$ \\
\hline Total & $\mathbf{2 0 ( 2 3 \% )}$ & $\mathbf{1 0 ( 1 2 \% )}$ & $\mathbf{1 2 ( 1 4 \% )}$ & $\mathbf{1 9 ( 2 2 \% )}$ & $\mathbf{1 0 ( 1 2 \% )}$ & $\mathbf{1 5}$ \\
\hline
\end{tabular}

Fuente: Cálculos propios a partir de entrevistas a madres titulares

Por otro lado, la desventaja más frecuentemente reportada por las madres entrevistadas relativa a la bancarización es el bloqueo de la tarjeta. Este bloqueo de la tarjeta puede estar asociado al olvido de la clave y a la falta de conocimiento y habilidad para el uso de cajeros electrónicos; esta última situación es de esperarse en individuos con poca ó nula experiencia con el sistema financiero formal; por tanto, la capacitación financiera es fundamental para insertar adecuadamente a las madres beneficiarias de programas de transferencias condicionadas en el sistema financiero. Con respecto a esta consideración, un estudio piloto sobre el uso de tarjetas electrónicas en programas de transferencias condicionadas, realizado para Jamaica, muestra que el $20 \%$ de los encuestados que reportó tener problemas con la tarjeta electrónica, manifestaron haber olvidado su clave o PIN (PATH, 2007). 
Vale la pena anotar que las madres tienen con frecuencia la percepción de pérdida del dinero o de recibir cantidades menores a las esperadas (Cuadro 28). Esta percepción puede estar asociada al hecho que las madres bancarizadas no reciben un reporte del ciclo y monto al que corresponde la consignación, ni una explicación que detalle la cifra entregada, como sucedía con el pago en efectivo. Esta falta de información les genera a las madres confusión y temores con el nuevo mecanismo de pago. Con relación a esta desventaja, en el estudio piloto de Jamaica las madres mencionaron también la importancia de tener un documento de reporte del pago, porque éste servía, además, como certificado para otros propósitos (PATH, 2007).

Mencionaron también la importancia de tener un documento de reporte del pago, porque éste servía, además, como certificado para otros propósitos (PATH, 2007).

\begin{tabular}{|c|c|c|c|c|c|c|}
\hline \multirow[t]{2}{*}{ comuna } & \multicolumn{6}{|c|}{$\begin{array}{l}\text { Desventajas del Pago con la Tarjeta del Banco Agrario (número de } \\
\text { madres) }\end{array}$} \\
\hline & Filas & $\begin{array}{l}\text { Bloqueo } \\
\text { de la } \\
\text { tarjeta }\end{array}$ & $\begin{array}{l}\text { Pagos } \\
\text { incompletos } \\
\text { o atrasados }\end{array}$ & $\begin{array}{l}\text { Percepción } \\
\text { de } \\
\text { que al dejar } \\
\text { el } \\
\text { dinero "se } \\
\text { pierde" }\end{array}$ & Otro & Ninguna \\
\hline Comuna 1 & --- & --- & --- & --- & --- & $6(100 \%)$ \\
\hline Comuna 2 & --- & $2(18 \%)$ & $2(18 \%)$ & --- & $5(45 \%)$ & 2 (18\%) \\
\hline Comuna 4 & $1(7 \%)$ & $3(21 \%)$ & $1(7 \%)$ & $2(14 \%)$ & $5(36 \%)$ & $2(14 \%)$ \\
\hline Comuna 9 & --- & $3(25 \%)$ & ---- & --- & --- & $9(75 \%)$ \\
\hline Comuna 14 & $1(9 \%)$ & --- & $2(18 \%)$ & $1(9 \%)$ & --- & $7(64 \%)$ \\
\hline $\begin{array}{l}\text { Otras } \\
\text { comunas }\end{array}$ & $2(13 \%)$ & 3 (19\%) & $2(13 \%)$ & $1(6 \%)$ & --- & $8(50 \%)$ \\
\hline Total & $4(6 \%)$ & $11(16 \%)$ & $7(10 \%)$ & $4(6 \%)$ & $1014 \%)$ & 34 (49\%) \\
\hline
\end{tabular}

Fuente: Cálculos propios a partir de entrevistas a madres titulares

Como se observa, hasta el momento de las entrevistas y a pesar de haber transcurrido poco tiempo desde la implementación del plan de bancarización, las madres entrevistadas reportan mejoras en bienestar asociadas a la reducción en tiempo para el retiro del subsidio, y se empiezan a visualizarlas ventajas de tener acceso al servicio financiero formal, al menos en términos de depósitos. 


\subsection{Análisis Gráficos}

Análisis Cuadro No. 7

\begin{tabular}{|c|c|c|}
\hline Comuna & $\begin{array}{c}\text { Ingresos } \\
\text { mensuales }\end{array}$ & $\begin{array}{c}\text { Gastos } \\
\text { mensuales }\end{array}$ \\
\hline Comuna 1 & 820.000 & 790.000 \\
\hline Comuna2 & 760.000 & 750.200 \\
\hline Comuna 4 & 730.520 & 690.500 \\
\hline Comuna 9 & 685.300 & 655.500 \\
\hline Comuna 14 & 920.000 & 800.370 \\
\hline Otras comunas & 720.560 & 710.000 \\
\hline Total & $\mathbf{7 7 2 . 7 3 0}$ & $\mathbf{7 3 2 . 7 6 2}$ \\
\hline
\end{tabular}

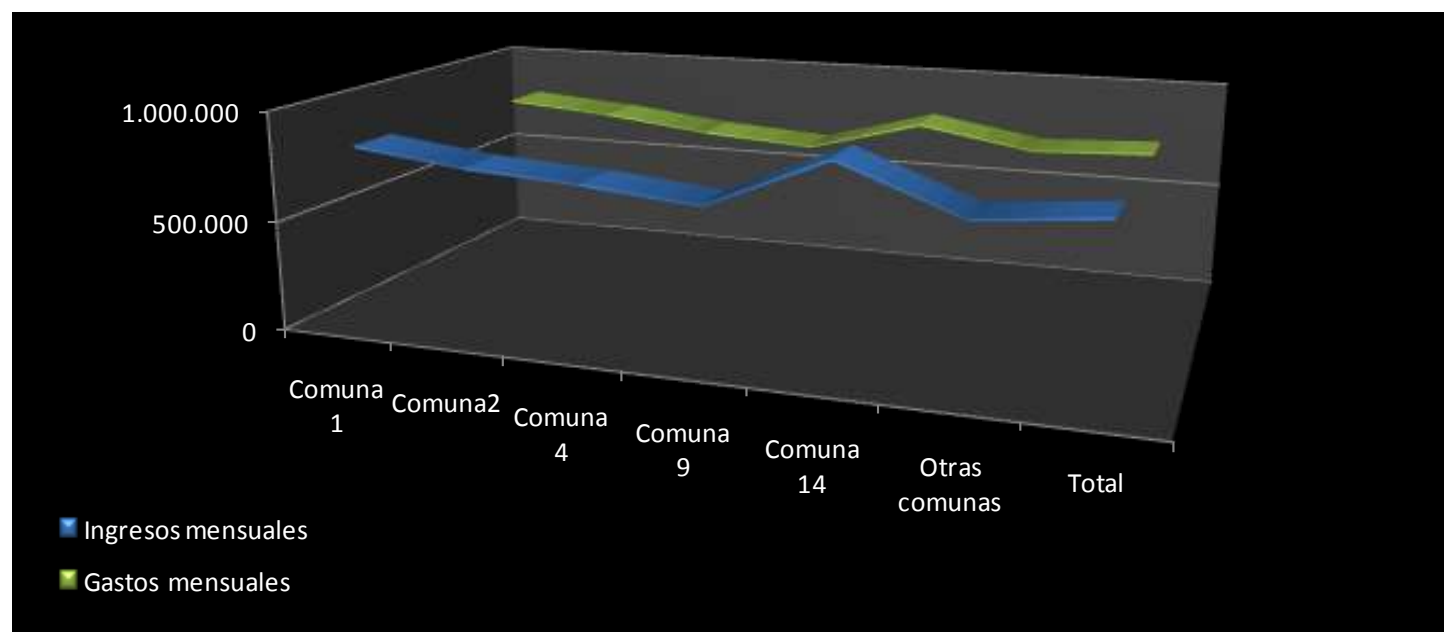

Al entrevistar las madres tenemos como resultado un promedio de ahorro de cincuenta y ocho mil pesos, al graficar los ingresos y los egresos promedio por comuna éste disminuye dicho porcentaje en un $45 \%$, los hogares como tal no alcanzan a ahorrar el $5 \%$ del valor de los ingresos 
Análisis Cuadro No. 8

\begin{tabular}{|l|c|c|c|c|c|c|c|}
\hline \multirow{3}{*}{ Total } & \multicolumn{7}{|c|}{ Como ahora ¿número de madres? } \\
\cline { 2 - 9 } & $\begin{array}{c}\text { Entidad } \\
\text { financiera } \\
\text { (depósitos) }\end{array}$ & $\begin{array}{c}\text { Alcancía o } \\
\text { efectivo }\end{array}$ & $\begin{array}{c}\text { Cadenas, } \\
\text { Fondos, } \\
\text { Tandas }\end{array}$ & $\begin{array}{c}\text { Materias } \\
\text { de } \\
\text { construcci }\end{array}$ & $\begin{array}{c}\text { Animales } \\
\text { doméstico } \\
\text { s }\end{array}$ & Otro & No ahorra \\
\cline { 2 - 9 } & $\mathbf{5}$ & $\mathbf{3 7}$ & $\mathbf{5}$ & $\mathbf{1}$ & $\mathbf{5}$ & $\mathbf{3}$ & $\mathbf{2 7}$ \\
\hline Comuna 1 & 1 & 1 & & & & & 4 \\
\hline Comuna 2 & 2 & 4 & 5 & 1 & 1 & & 2 \\
\hline Comuna 4 & 1 & 6 & & & 2 & & 5 \\
\hline Comuna 9 & & 7 & & & & 1 & 5 \\
\hline Otras 14 & 1 & 7 & & & 1 & 2 & 4 \\
\hline Total & $\mathbf{5}$ & $\mathbf{3 7}$ & $\mathbf{5}$ & $\mathbf{1}$ & $\mathbf{5}$ & $\mathbf{3}$ & $\mathbf{2 7}$ \\
\hline
\end{tabular}

\section{¿ Como Ahorran?}

r Entidad financiera (depósitos)

m Cadenas, Fondos, Tandas

m Animales domésticos

m No ahorra
* Alcancía o efectivo

* Materias de construcción

n Otro

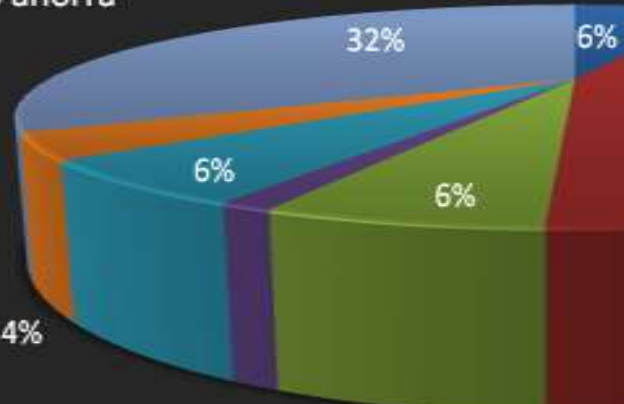

$1 \%$

La desconfianza hacia el sector financiero, los altos costos como consulta de saldos y retiros, son los factores que más inciden en los hogares. Las madres prefieren el ahorro tradicional de las alcancías. 
Análisis Cuadro No. 12

\begin{tabular}{|l|r|r|r|c|}
\hline Comuna & $\begin{array}{c}\text { Ahorros } \\
\text { promedio } \\
\text { por mes }\end{array}$ & Máximo & Mínimo & OBSERVACIONES \\
\hline Comuna 1 & $\$ 30.000$ & $\$ 30.000$ & $\$ 30.000$ & 01 -jun \\
\hline Comuna 2 & $\$ 63.314$ & $\$ 180.000$ & $\$ 20.000$ & $07-$ sep \\
\hline Comuna 4 & $\$ 37.111$ & $\$ 70.000$ & $\$ 10.000$ & sep-14 \\
\hline Comuna 9 & $\$ 59.500$ & $\$ 100.00$ & $\$ 10.000$ & oct-13 \\
\hline Comuna & $\$ 50.714$ & $\$ 125.000$ & $\$ 15.000$ & $07-$ nov \\
\hline Otras & $\$ 77.500$ & $\$ 250.000$ & $\$ 10.000$ & $14 / 20$ \\
\hline Total & $\mathbf{\$ 5 8 . 1 5 6}$ & $\mathbf{\$ 2 5 0 . 0 0 0}$ & $\mathbf{\$ 1 0 . 0 0 0}$ & $\mathbf{4 8 / 7 3}$ \\
\hline
\end{tabular}

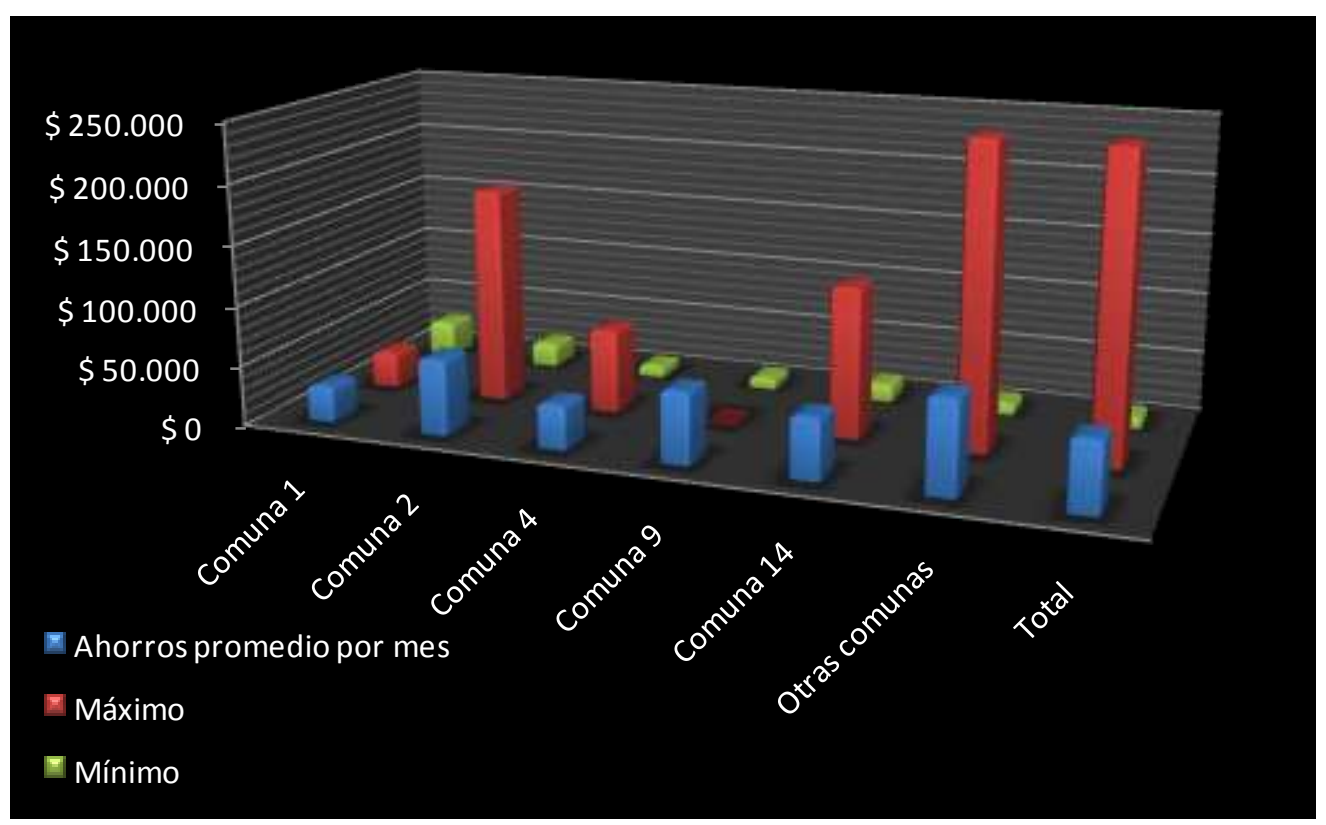

La cultura de ahorro es mínima, la gran mayoría de los hogares es para inversión como arreglo de casa, compra de electrodoméstico o viaje familiar; este porcentaje de ahorro según el ingreso promedio de los hogares no supera el $5 \%$ de los ingresos siendo muy bajo. 


\section{Análisis De Cuadro No. 15}

\begin{tabular}{|l|r|r|l|r|}
\hline \multicolumn{1}{|c|}{ Total } & $\begin{array}{c}\text { Monto } \\
\text { promedio } \\
\text { solicitado }\end{array}$ & $\begin{array}{c}\text { Pago diario } \\
\text { promedio }\end{array}$ & $\begin{array}{c}\text { Interés } \\
\text { promedio } \\
\text { mensual }\end{array}$ & $\begin{array}{c}\text { Plazo } \\
\text { promedio } \\
\text { para pago }\end{array}$ \\
\hline Comuna 1 & 280.000 & 6.000 & 6.25 & 90 \\
\hline Comuna 2 & 100.000 & 4.000 & 20.00 & 30 \\
\hline Comuna 4 & 135.714 & 4.857 & 19.30 & 31 \\
\hline Comuna 9 & 150.000 & 3.800 & 15.00 & 42 \\
\hline Comuna 14 & 177.778 & 5.222 & 13.90 & 48 \\
Total & $\mathbf{1 6 5 . 0 0 0}$ & $\mathbf{4 . 7 8 3}$ & $\mathbf{1 5 . 3 1}$ & $\mathbf{4 5}$ \\
\hline
\end{tabular}

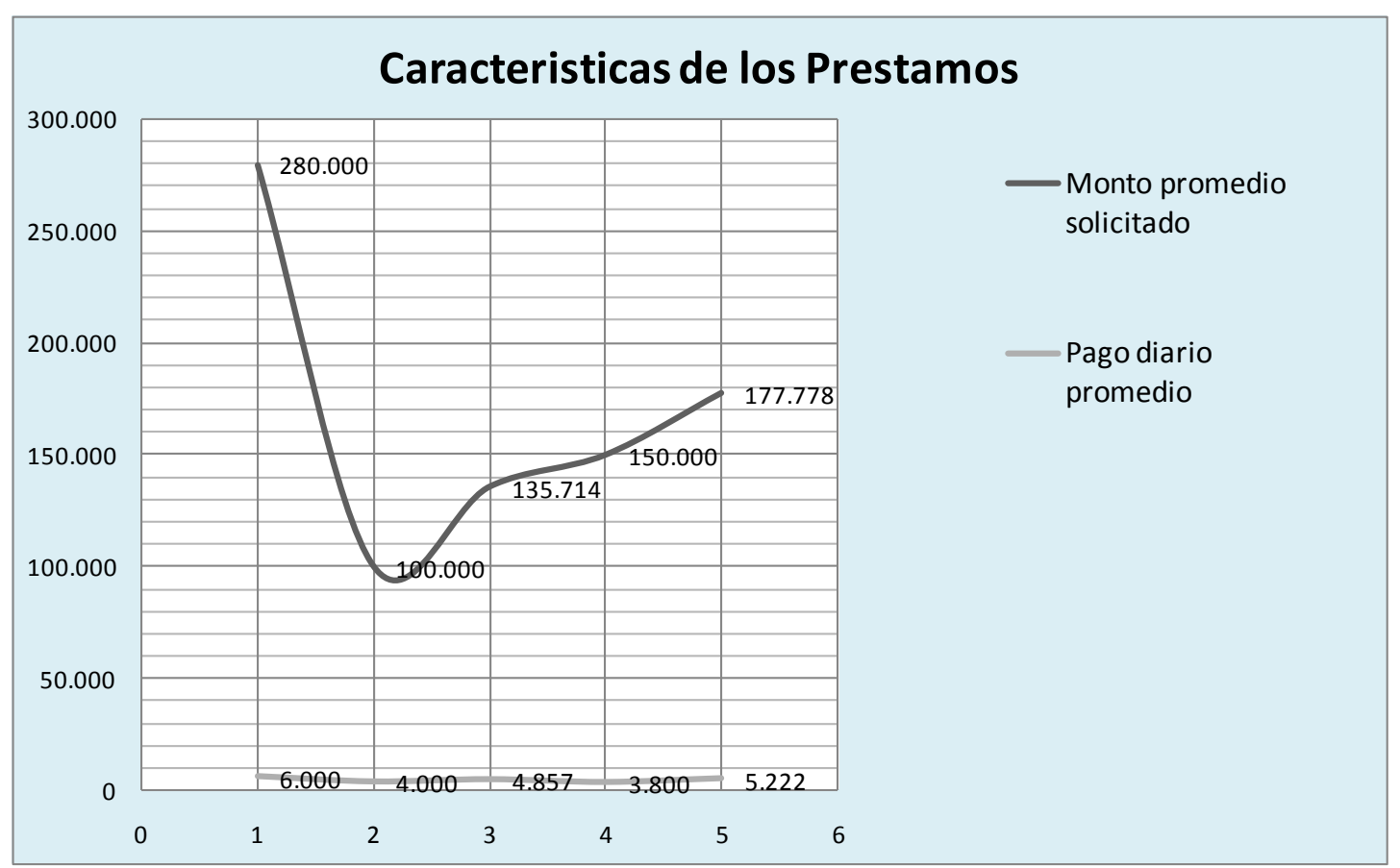

Los hogares prefieren el crédito inmediato. No importa el alta tasa de interés, el paga diario, el gota a gota en estos sectores son los más usados debido a la tramitología del sector financiero no permite que los hogares tengan líneas de crédito, como se puede ver el promedio de préstamo no supera el $20 \%$ del total de los ingresos promedio de cada hogar. 


\subsection{La Bancarización}

Las madres encontraron en la bancarización varias ventajas, entre las que se destaca la posibilidad de mantener su dinero en una cuenta de ahorros. El pago del subsidio a través de un tarjeta electrónica también les permite ahorrar tiempo (reducción en filas y congestión) -que pueden dedicar a sus hijos o a sus actividades ocupacionales-, retirar el dinero del subsidio de acuerdo a su conveniencia en términos de tiempo y mayor humanización del proceso, en el sentido que no deben soportar, por ejemplo, las inclemencias del clima y se eliminan los conflictos con otras madres durante las esperas en fila.

Por otro lado, la percepción de las madres relacionada con consignaciones incompletas del subsidio

- la "pérdida de dinero" bajo el mecanismo de bancarización puede explicarse por la incertidumbre que les genera a las madres no recibir, como sucedía con el mecanismo del pago en efectivo, un reporte escrito que les aclare cuál es el ciclo de pago que están recibiendo y cómo está liquidado ese ciclo. En un estudio similar realizado en Jamaica (PATH, 2007), se encontró que estos reportes de pago son importantes para los beneficiarios, porque los utilizan no solo para tener información detallada del pago, sino como "certificado" de que son beneficiarios del programa de subsidios, en casos donde esa filiación puede ser relevante. Este es un aspecto que el programa FA deberá considerar para mejorar la prestación de sus servicios.

Este análisis cualitativo revela varios aspectos que deben profundizarse en torno al propósito de favorecer el acceso real de población vulnerable, como los hogares pertenecientes al programa de FA, a servicios financieros: i) a menos de un año de iniciado el plan de bancarización, las madres beneficiarias reconocen varios beneficios, siendo el principal acceder a una cuenta de ahorros; ii)más allá de mejorar la eficiencia en la entrega del subsidio, la bancarización se justifica por la necesidad que tienen los hogares de acceder a servicios financieros de diferente índole, necesidad que se refleja en la amplia variedad de estrategias de ahorro y crédito con las que cuentan los hogares beneficiarios de FA, la mayoría informales y algunas de ellas con altos costos; iii) el plan de bancarización del programa FA podría 
constituirse en el primer paso para favorecer la inserción efectiva de hogares pobres en el sistema financiero formal en Colombia.

No obstante, el acceso efectivo de estas madres al sistema financiero requiere de capacitación financiera adecuada y adaptada a sus necesidades. Como se presenta en este estudio uno de los principales problemas que enfrentan las madres es el bloqueo de la tarjeta. A pesar de que el plan de bancarización del programa FA incluyó jornadas de apertura de cuentas, donde se explicaba el funcionamiento de la tarjeta, éstas no fueron jornadas de alfabetización financiera en el sentido estricto. Varias madres manifestaron no entender exactamente los beneficios y funcionamiento ni de La tarjeta electrónica entregada ni de la cuenta de ahorros. De hecho, algunas entrevistadas

Declararon entregar su tarjeta y su clave a la madre líder, amigos o familiares -incluso a desconocidos-, o pagar por este servicio ("servicio" de retirar su dinero) debido al temor que les genera hacer el procedimiento ellas mismas y bloquear la tarjeta. Esta situación indicaría también

Las madres entrevistadas hicieron varias sugerencias para mejorar la efectividad de la "capacitación" financiera, que vale la pena tener presentes en éste y otros ejercicios de bancarización de poblaciones de bajos ingresos. Las madres sugieren recomendaciones de tipo logístico y respecto a la forma en que es suministrada la información de la cuenta de ahorros. Con respecto a las recomendaciones de tipo logístico, mencionan aspectos básicos como tener en cuenta el número de personas por jornada y mejorar el sonido en los cajeros electrónicos y la selección de sitios para la capacitación; con respecto a la forma en que la información financiera es suministrada, sugieren hacer explicaciones más detalladas, hacer prácticas de uso del cajero electrónico con "cajeros demostrativos", utilizar variadas herramientas pedagógicas y un espacio durante la misma jornada para solución de dudas e inquietudes.

Aunque las jornadas de apertura de cuentas no se diseñaron como jornadas de alfabetización o educación financiera sino como jornadas cuyo propósito principal era la apertura de cuentas para las

Madres beneficiarias, la información oral y escrita suministrada a las madres sobre la cuenta de ahorros y el manejo de la tarjeta electrónica, se puede considerar información financiera 
La capacitación financiera para adultos de bajos ingresos debe tener ciertas características como aquellas mencionadas por Gómez-Soto (2009), entre las que se encuentran: i) contenidos prácticos, de utilidad inmediata y accesible inclusive para analfabetos.

De acuerdo a la OECD (2005, citado por Gómez-Soto, 2009), la educación financiera se define como "el proceso por el cual los consumidores financieros e inversores mejoran su comprensión de los productos y conceptos financieros a través de información, instrucción y/o consejo objetivo, desarrollan habilidades y confianza para conocer mejor los riesgos y oportunidades financieras, tomar decisiones informadas, saber donde obtener ayuda y tomar otras decisiones efectivas que les permitan mejorar su condición financiera(OECD, 2005)".

Una capacitación cuidadosamente preparada, tanto en aspectos logísticos como de contenido, podría evitar altos costos de transacción asociados a los desbloqueos de tarjetas tanto para las entidades involucradas en el proceso como para las madres beneficiarias, quienes no asumirían riesgos ni costos innecesarios, como solicitar a terceras personas el favor de retirar el dinero o pagar por ese servicio. La comprensión por parte de las madres de los beneficios y el funcionamiento de su cuenta de ahorros favorecerá la incorporación efectiva de estos hogares en el sistema financiero formal y el uso de sus productos y servicios.

Finalmente, se resalta la importancia del levantamiento y análisis de información cualitativa para entender con mayor profundidad la situación estudiada y complementar información estrictamente cuantitativa proveniente de bases de datos, en estudios, como éste, en los que los detalles y la 'historia' alrededor de cada pregunta enriquecen la comprensión del contexto de análisis.

\subsection{Discusión Final}

Debido a la focalización del programa FA, las madres y sus familias pertenecen a una población considerada de alta vulnerabilidad. Este informe muestra que la mayoría de madres entrevistadas y sus cónyuges reportaron solamente dos posiciones ocupacionales, ambas caracterizadas por inestabilidad y alta informalidad: trabajador independiente (trabajos por día como empleadas domésticas, oficios varios, obreros) y negocio propio 
(vendedores informales de alimentos, hielo, minutos de celular, mototaxismo, etc.). Los ingresos mensuales reportados por las madres entrevistadas, no superan en promedio el salario mínimo mensual vigente y sus niveles de gasto mensual les dejan un margen estrecho para destinar a ahorro 0 inversión.

A pesar de estas restricciones, más de la mitad de las mujeres entrevistadas manifiesta ahorrar de manera formal o informal, sobresaliendo el ahorro "en alcancía" o "en efectivo" como el mecanismo de ahorro más reportado. Ahorros en "ladrillos" (materiales de construcción) y animales domésticos como cerdos o gallinas, que han sido reportados para otros países (Rosenzweig yWolpin, 1993;Fafchampset al., 1998), también se encontraron entre las madres beneficiarias del programa FA. Sin embargo, los "ahorros en ladrillos", como lo mencionan Duryea y Schargrodsky(2008), no constituyen ahorros suficientemente líquidos para responder rápidamente a las necesidades de consumo vigentes y se mantienen como ahorros de "largo plazo". Varias madres afirmaron, sin embargo, que debido precisamente a limitaciones de tipo económico, no ahorraban de ninguna forma.

Las madres utilizan sus ahorros principalmente como forma de anticipar imprevistos (ahorros preventivos) y para cubrir necesidades de sus hijos (alimentación, educación y vestuario). Los ahorros suavizan la senda de consumo del hogar en situaciones inesperadas y no controlables como Calamidades domésticas, así como situaciones previstas tales como gastos escolares de principio de año y gastos de vestuario al final del mismo. No obstante, las madres utilizan sus ahorros para variados fines, incluido el pago de deudas y de servicios públicos, cuando es necesario.

Como se observa de los resultados presentados en este documento, la informalidad caracteriza las estrategias de ahorro de las madres, mientras que los ahorros reportados de entidades formales son más escasos, aunque no menos importantes. Entre éstos, vale la pena destacar el caso de algunas madres que reportaron pertenecer al programa Madres Ahorradoras en Acción, es decir existió un ahorro forzado para poder obtener un incentivo extra en este programa, pero como conclusión final se puede demostrar que el $24 \%$ de las madres encuestadas manifestaron que si se puede ahorrar por medio del sistema financiero de bancarización, pero lo como el ahorro es mínimo, y las entidades financieras no están a su alcance de ubicación, el 
costo de desplazamiento hacia la entidad no motiva a depositar un ahorro mínimo, tal esa así que prefieren la alcancía o ahorro en un lugar estratégico, cajón o colchón.,

Los ahorros promedio de las madres oscilan entre $\$ 2.000$ y $\$ 3.000$ pesos diarios, indicando que programas que estimulen el ahorro de esta población deben tener en cuenta esta característica. Por ejemplo en el caso del programa presidencial Mujeres Ahorradoras en Acción, las madres microempresarias se comprometen a ahorrar $\$ 1.500$ diarios durante tres meses, en una alcancía otorgada por el programa, para depositarlos en una cuenta de ahorros a su nombre, que es congelada durante nueve meses. Después de ese periodo, el gobierno otorga un subsidio a las madres, equivalente al $50 \%$ del valor ahorrado. De acuerdo a nuestros resultados, la cifra determinada por este programa de ahorro estaría adecuadamente asignada o estaría muy cercana a la capacidad y mecanismo de ahorro de las madres.

Las madres mencionan razones similares a las reportadas en otros estudios para poblaciones de bajos ingresos para no ahorrar en entidades financieras (FELABAN, 2007; Kumar, 2005): excesivos trámites y documentos para abrir la cuenta, insuficiencia de recursos para ahorrar, desconfianza en las entidades informales y altos costos asociados al manejo de la cuenta de ahorros, entre otros. De la misma manera como las madres ahorran, formal e informalmente, acceden al crédito. Una forma de crédito muy importante para estas madres es solicitar préstamos, generalmente por muy cortos periodos de tiempo, a amigos o familiares. Este tipo de préstamos soluciona necesidades de dinero pequeñas y en su mayoría se caracterizan por bajos o nulos intereses. Esta estrategia para acceder al crédito, así como algunas estrategias para superar shocks y eventos que se discutirán más adelante, se relaciona con el capital social establecido y acumulado -normas y redesen las comunidades donde se desenvuelven estas madres. Aspectos de capital social como las normas informales establecidas, relacionadas con reciprocidad y solidaridad, las redes de amigos, vecinos y nodos de redes sociales como el "tendero", pueden tener un efecto importante en la suavización del consumo mediante este tipo de préstamos. Un aspecto que desafortunadamente no se preguntó explícitamente en las entrevistas, pero que fue mencionado por las madres, es el consumo de víveres "al fiado", que parece ser una estrategia funcional, oportuna y ajustada a los flujos e inestabilidad en los ingresos de estos hogares. 
Las madres también manifestaron solicitar dinero bajo las modalidades de gota a gota (o paga diario) y empeño. Un poco menos de la mitad de las madres entrevistadas ha acudido al préstamo gota agota, principalmente para pagar los servicios públicos e, interesantemente, para surtir los negocios propios del hogar. Esta modalidad de crédito es, entre las reportadas, la que se asocia a mayores tasas de interés, usualmente por encima de la tasa de usura legal (en promedio15, 3\% mensual); aún así, las madres recurren a este mecanismo por su oportunidad: está disponible cuando lo requieren sin la necesidad de trámites, documentos, garantías, ni fiador. Además, aunque el repago es usualmente diario, el cobrador va directamente a la casa del deudor, lo que reduce los costos de transacción de ir hasta la oficina a pagar. Este tipo de préstamos tienen plazos de pago cortos (en promedio de un mes y medio) y cuotas diarias (incluidos los intereses) de, en promedio, $\$ 4.800$, muy por encima de la capacidad de ahorro, diario promedio que encontramos durante las entrevistas en el orden de 2.000 y $-\$ 2.500$.

Nótese que, a pesar de los altos intereses, varias madres acuden a los préstamos gota a gota para invertir en sus pequeños negocios; esta situación da luces acerca de cómo los mecanismos de crédito formal, particularmente microcrédito orientado a estas pequeñas empresarias, pueden llenar estos espacios. De hecho, como se muestra en este informe, varias madres han accedido a crédito formal en entidades de micro finanzas orientadas a apoyar los pequeños negocios de mujeres, como lo hace la Fundación Mundo Mujer.

Otro modalidad de préstamos reportado por la madres es el empeño de joyas o bienes del hogar. Casi la mitad de las madres entrevistadas ha solicitado dinero bajo esta modalidad, siendo las joyas el bien más empeñado. A diferencia de la modalidad gota a gota, el uso más frecuentemente reportado para el dinero solicitado a través de empeño son shocks idiosincráticos (imprevistos o calamidad doméstica), entre los que se encuentran accidentes, muerte o enfermedad. Los intereses pagados mensualmente bajo esta modalidad ( $9,5 \%$ mensual promedio), aunque son más bajos que en la modalidad gota a gota, son muy superiores a los intereses de las entidades formales de crédito. 
Curiosamente, aunque los montos promedio solicitados en empeño (en promedio, \$104.000) son menores a los del gota a gota (en promedio $\$ 165.000$ ), los plazos de pago promedio reportados son mayores en el primero (120 días versus 45 días del gota a gota). Desafortunadamente, esta estrategia conduce en varios de los casos a la pérdida de los bienes del hogar.

Con respecto a los mecanismos para enfrentar shocks y anticiparse a eventos, vale la pena destacar otra vez el papel del capital social en las estrategias. Cuando las madres se enfrentan a shocks inesperados, como muerte o enfermedad, acuden con mayor frecuencia a familiares y amigos para solicitar préstamos o ayudas. Adicionalmente, las madres manifestaron que varios shocks fueron superados gracias a "colectas" de dinero realizadas también entre amigos y familiares.

Confirmando los resultados del uso de ahorros y de préstamos bajo la modalidad de empeño, las madres también destacan estas dos estrategias para superar shocks idiosincráticos e imprevistos.

A diferencia de las estrategias para enfrentar shocks, el principal mecanismo para anticiparse a eventos previstos y celebraciones es el ahorro y otra vez, las colectas entre familiares.

\subsection{Conclusiones}

Desde el punto de vista como administrador y coordinador del programa Más Familias en Acción de Bucaramanga se percibe el desarrollo de éste programa social como la solución a gran parte de los hogares desde el punto de vista económico, una vez realizada la encuesta y escuchando, analizando , tabulando y comprendiendo los resultados vemos que en los hogares el ingreso recibido vs el ingreso real no llega éste a los dos dígitos, tan es así que la población vulnerable utiliza en gran parte en la jornada no académica a los jóvenes para realizar tareas que permitan un ingreso extra.

La cultura de ahorro en cada uno de los hogares es mínima, casi que podemos decir escasa, el programa como tal buscó por medio del programa de bancarización que cada familia pudiera tener acceso al sistema financiero, fueron capacitadas, exonerada de impuestos logrando así, que a si fuera mínimo el ahorro lo hiciera. Pero la desconfianza hacia el sector financiero, el 
escaso ingreso de efectivo a los hogares, el desempleo, la falta de oportunidades y el gasto excesivo no permite que el ahorro sea factor importante en el hogar.

En el Municipio de Bucaramanga, en el sector oficial los jóvenes que se gradúan que pertenecen al programa Mas Familias en acción es de 485, de los cuales el $35 \%$ complementa sus estudios de nivel académico tecnológico en el SENA en los programas de Jóvenes en Acción, del cual el gobierno Nacional les otorga un subsidio de $\$ 200$ mil que garantiza el transporte y textos académicos durante un año mínimo y máximo dos, hasta alcanzar la tecnología.

El 5\% de los graduandos accede a la Universidad oficial en este caso la UIS, y solo el $1 \%$ a educación superior privada.

Finalmente concluyo en esta investigación que son las faltas de oportunidades, como generación de empleo herramientas complementarias de este programa como la educación de jóvenes en acción que permitan capacitar al ciudadano común para un empleo óptimo. El SENA esta desarrollando una plataforma que permite garantizar su primer empleo a jóvenes que se gradúen del programa jóvenes en acción y facilitándole mediante becas acceder la educación superior, esta es una herramienta complementaria en el desarrollo de estos programas sociales.

La hipótesis planteada no se valida, sino que se presentan datos que permitieron mostrar el comportamiento del ingreso en el hogar y la participación del mismo en la familia, de igual forma se puede demostrar la capacidad de ahorro del hogar en el sistema financiero.

El presente estudio es entregado al Sr. Alcalde de Bucaramanga para articular un programa educativo de nivel tecnología con la Universidad del Pueblo, programa modelo a nivel municipal, permitiéndole herramientas a los hogares de escasos recursos, donde se le siguiere garantizar el transporte a cada joven beneficiario. 


\section{BIBLIOGRAFIA}

Alderman, H. \& C. Paso. 1994. "Do the poor insure? A Synthesis of the Literature on Risk and Consumption in Developing Countries", International Economics Association Moscow, vol.4.

Attanasio, Orazio, and Katja Kaufmann. 2008. "Educational Choices, Subjective Expectations and Credit Constraints." Unpublished manuscript, University College, London.

Behrman, J.R., Sengupta, P. and Todd, P.E., (2005). Progressing through PROGRESA - An Impact Assessment of a School Subsidy Experiment in Rural Mexico. Economic Development and Cultural Change 54 (1), 237-75.

Behrman, J.R., Sengupta, P. and Todd, P.E. (2000). The Impact of PROGRESA on Achievement Test Scores in the First Year. Unpublished Manuscript, International Food Policy Research Institute, Washington DC.

Deaton, A. 1991. "Savings and Liquidity Constraints", Econometrica, vol.59, no.5, 1221-48.

Deaton, A. 1992. "Household Saving in LDCs: Credit Markets, Insurance and Welfare." Scandinavian Journal of Economics, 94 (1992): 253-73.

Dercon, S. 1996. "Risk, Crop Choice and Savings: Evidence from Tanzania", Economic Development and Cultural Change, 44(3):485-514.

Dercon, S. 2002. "Income risk, coping strategies and safety nets". The World Bank Research Observer, 17(2): 141-166.

De Janvry, A., Finan, F, Sadoulet, E., Vakis, R. (2006). Can conditional cash transfer programs serve as safety nets in keeping children at school and from working when exposed to shocks? Journal of Development Economics 79, 349 - 373.

Glewwe, P. and Olinto, P. (2004). Evaluating the Impact of Conditional Cash Transfers on Schooling - An Experimental Analysis of Honduras. Unpublished Manuscript, University of Minnesota, Minneapolis.

Jensen, Robert. 2006. "Do the Perceived Returns to Education Affect Schooling Decisions? Evidence from a Randomized Experiment." Unpublished manuscript, Harvard University, Cambridge, MA.

Hernandez sampiere; Roberto; Fernandez Collado, Carlos Baptista Lucio, Pilar (2010)Metodologia de la Investigaciòn . Mc Graw Hill, Quinta Ediciòn , Mexico.

Levy, D. and Ohls, J. (2010). Evaluation of Jamaica's PATH conditional cash transfer programme. Journal of Development Effectiveness 2 (4), 421-441. 
Macours, K. Schady and Vakis, R. (2008). Changing Households' Investments and Aspirations through Social Interactions - Evidence from a Randomized Transfer Program in a Low-Income Country. Unpublished Manuscript, Johns Hopkins University, Baltimore MD, and World Bank, Washington, DC.

Maluccio, J.A. and Flores, R. (2005). Impact Evaluation of a Conditional Cash Transfer Program - The Nicaraguan Red de Protección Social. Research Report 141, International Food Policy Research Institute, Washington DC.

Morduch, J. 1995. "Income Smoothing and Consumption Smoothing." Journal of Economic Perspectives, 9: 103-14.

Rawlings, Laura. 2004. "Conditional Cash Transfer Programs: Experimenting with Service Delivery Alternatives. World Bank, Latin America and Caribbean Region, Human Development Department, Washington, D.C.

Rawlings, L. B., \& Rubio, G. M. (2005). Evaluating the impact of conditional cash transfer programs. The World Bank Research Observer, 20(1), 29-55.

Rosenbaum, P.R. and Rubin, D.B. (1983). The Central Role of the Propensity Score in Observational Studies for Causal Effects. Biometrika 70 (1), 41-55.

Rosenzweig, M. \& H. Binswanger. 1993. "Wealth, Weather Risk and the Composition and Profitability of Agricultural Investments", Economic Journal, 103: 56-78.

Schady, N. and Araujo, M.C. (2008). Cash Transfers, Conditions, and School Enrollment in Ecuador. Economía 8 (2), 43-70.

Schultz, T. Paul. 2000. "Final Report: The Impact of Progresa on School Enrollments. International Food Policy Research Institute, Washington, D.C.

Schultz, T.P. (2004). School Subsidies for the Poor - Evaluating the Mexican PROGRESA Poverty Program. Journal of Development Economics 74 (1), 199-250.

Skoufias, E. 2001. "Progresa and Its Impacts on the Human Capital and Welfare of Households in Rural Mexico: A Synthesis of the Results of an Evaluation by IFPRI. International Food Policy Research Institute, Washington, D.C.

World Bank. 2010. "Brazil: An Assessment of the Bolsa Escola Programs. Human Development Department, Latin America and Caribbean Region, Washington, D.C.

Yap, Yoon-Tien, Guilherme Sedlacek, and Peter Orazem. 2001. "Limiting Child Labor through Behavior- Based Income Transfers: An Experimental Evaluation of the PETI Program in Rural Brazil. World Bank, Washington, D.C. 